\title{
A global off-line model of size-resolved aerosol microphysics: II. Identification of key uncertainties
}

\author{
D. V. Spracklen, K. J. Pringle, K. S. Carslaw, M. P. Chipperfield, and G. W. Mann \\ Institute for Atmospheric Science, School of Earth and Environment, University of Leeds, UK
}

Received: 21 January 2005 - Published in Atmos. Chem. Phys. Discuss.: 30 May 2005

Revised: 24 October 2005 - Accepted: 14 November 2005 - Published: 6 December 2005

\begin{abstract}
We use the new GLOMAP model of global aerosol microphysics to investigate the sensitivity of modelled sulfate and sea salt aerosol properties to uncertainties in the driving microphysical processes and compare these uncertainties with those associated with aerosol and precursor gas emissions. Overall, we conclude that uncertainties in microphysical processes have a larger effect on global sulfate and sea salt derived condensation nuclei $(\mathrm{CN})$ and cloud condensation nuclei $(\mathrm{CCN})$ concentrations than uncertainties in present-day sulfur emissions. Our simulations suggest that uncertainties in predicted sulfate and sea salt CCN abundances due to poorly constrained microphysical processes are likely to be of a similar magnitude to long-term changes in sulfate and sea salt CCN due to changes in anthropogenic emissions. A microphysical treatment of the global sulfate aerosol allows the uncertainty in climate-relevant aerosol properties to be attributed to specific processes in a way that has not been possible with simpler aerosol schemes. In particular we conclude that: (1) changes in the binary $\mathrm{H}_{2} \mathrm{SO}_{4}$ $\mathrm{H}_{2} \mathrm{O}$ nucleation rate and condensation rate of gaseous $\mathrm{H}_{2} \mathrm{SO}_{4}$ cause a shift in the vertical location of the upper tropospheric $\mathrm{CN}$ layer by as much as $3 \mathrm{~km}$, while the shape of the CN profile is essentially pre-served (2) uncertainties in the binary $\mathrm{H}_{2} \mathrm{SO}_{4}-\mathrm{H}_{2} \mathrm{O}$ nucleation rate have a relatively insignificant effect on marine boundary layer (MBL) aerosol properties; (3) emitting a fraction of anthropogenic $\mathrm{SO}_{2}$ as particulates (to represent production of sulfate particles in power plant plumes below the scale of the model grid (which is of the order of $300 \mathrm{~km}$ )) has the potential to change the global mean MBL sulfate-derived CN concentrations by up to $72 \%$, and changes of up to a factor 20 can occur in polluted continental regions; (4) predicted global mean MBL sulfate and sea salt CCN concentrations change by 10 to $60 \%$ when several microphysical processes are changed within reasonable uncer-
\end{abstract}

Correspondence to: D. V. Spracklen

(dominick@env.leeds.ac.uk) tainty ranges; (5) sulfate and sea salt derived $\mathrm{CCN}$ concentrations are particularly sensitive to primary particle emissions, with global mean MBL sulfate and sea salt CCN changing by up to $27 \%$ and local concentrations over continental regions changing by more than $100 \%$ when the percentage of anthropogenic $\mathrm{SO}_{2}$ emitted as particulates is changed from 0 to $5 \%$; (6) large changes in sea spray flux have insignificant effects on global sulfate aerosol except when the mass accommodation coefficient of sulfuric acid on the salt particles is set unrealistically low.

\section{Introduction}

Several global aerosol models have recently been developed that include a full size-resolved (sectional) treatment of the aerosol mass and number (Gong et al., 1997, 2003; Jacobson, 2001; Adams and Seinfeld, 2002, 2003; Spracklen et al., 2005). Although global simulations with these models have mostly been restricted to just sea salt (Gong et al., 1997), sulfate (Adams and Seinfeld, 2002) or their combination (Adams and Seinfeld, 2003; Gong et al., 2003; Spracklen et al., 2005), much has been learned about the factors that control the aerosol size distribution in different atmospheric regions. These global sectional aerosol models calculate aerosol properties from first principles without making assumptions about the shape of the size distribution. Once these models have been evaluated against modern observations they should be useful tools for calculating global cloud condensation nuclei $(\mathrm{CCN})$ concentrations without the need for simple parameterisations relating aerosol mass or number to $\mathrm{CCN}$ number. This is an important development as a better estimation of the anthropogenic effects on $\mathrm{CCN}$ number is essential for quantification of the aerosol indirect effect.

An essential part of the development of these models is to quantify the robustness of the predicted aerosol size distribution, given quite large uncertainties in microphysical

(C) 2005 Author(s). This work is licensed under a Creative Commons License. 
processes and emissions. This paper is the second of three papers describing a new GLObal Model of Aerosol Processes (GLOMAP). The first paper described the model and the global simulation of sulfate and sea salt aerosol properties (Spracklen et al., 2005). This second paper examines the sensitivity of the predicted aerosol size and spatial distribution to uncertainties in the microphysical processes that control these two aerosol types. The third paper will present a detailed comparison of the model against aerosol observations.

Sensitivity studies of direct radiative forcing have generally shown a weak dependence on the assumed aerosol size distribution (Kiehl and Briegleb, 1993; Boucher and Anderson, 1995; Nemesure et al., 1995; Pilinis et al., 1995; Pan et al., 1997). In contrast to these earlier studies, Myhre et al. (2004) showed that relatively small changes in size distribution can change the direct radiative forcing by up to $15 \%$. Sensitivity studies of indirect radiative forcing by sulfate aerosols show that uncertainty in the shape of the aerosol distribution is one of the largest contributors to model uncertainty (Pan et al., 1998), indicating that size-resolved global aerosol models are required for an accurate description of indirect radiative forcing.

Aerosol box models have been used to understand the processes controlling aerosol properties in the remote marine boundary layer (MBL) (Pandis et al., 1994; Raes, 1995; Kerminen and Wexler, 1997; Capaldo et al., 1999; Yoon and Brimblecombe, 2002). Raes (1995) showed that the sensitivity of MBL number concentration to the accommodation coefficient and nucleation rate was small compared to the sensitivity to environmental variables such as the rate of entrainment of aerosol from the free troposphere (FT). For example, both Raes (1995) and Capaldo et al. (1999) showed that entrainment of FT aerosol into the MBL could suppress MBL aerosol nucleation. However, Capaldo et al. (1999) also showed that modelled MBL aerosol number depended sensitively on the $\mathrm{H}_{2} \mathrm{SO}_{4}$ accommodation coefficient, nucleation rate and washout efficiency.

Adams and Seinfeld (2002) used a global aerosol model to show that both condensation nuclei $(\mathrm{CN})$ and $\mathrm{CCN}$ concentrations are sensitive to changes in the assumed nucleation rate and to primary particulate emissions from anthropogenic sulfur emissions. Here, we use GLOMAP to explore the sensitivity to a much larger range of microphysical processes affecting sulfate and sea salt aerosol and compare the resulting changes in $\mathrm{CN}$ and $\mathrm{CCN}$ with those due to uncertainties in emissions of both sulfur species and sea spray.

\section{Model description}

GLOMAP is an extension to the TOMCAT global 3-D offline chemical transport model (CTM) (Stockwell and Chipperfield, 1999). GLOMAP includes the processes of aerosol nucleation, condensation, growth, coagulation, wet and dry deposition, transport, and cloud processing. A full descrip- tion of GLOMAP is given in Spracklen et al. (2005). The aerosol distribution is described using a sectional scheme with 20 bins spanning dry diameters from about $1 \mathrm{~nm}$ to $25 \mu \mathrm{m}$. Two moments are simulated in each section (number density and mass per particle). GLOMAP, as used here, is currently restricted to sea salt and sulfate aerosol.

Spracklen et al. (2005) showed that GLOMAP is capable of simulating realistic MBL CN and CCN concentrations under conditions where sulfate and sea salt are the dominant components of the aerosol. In the MBL the model simulates the submicron bimodal distribution with Aitken mode and accumulation mode simulated at approximately the correct sizes. In the lower FT the model simulates a unimodal distribution.

In this study we use a spatial resolution of $2.8^{\circ} \times 2.8^{\circ}$ latitude $\times$ longitude with 31 hybrid $\sigma-$ p levels extending from the surface to $10 \mathrm{hPa}$. In the experiments performed here large-scale atmospheric transport is specified from European Centre for Medium-Range Weather Forecasts (ECMWF) analyses at 6-hourly intervals. The model was initialised with an aerosol-free atmosphere (on 1 October 1995) and spun up for 45 days before sensitivity studies were started.

$\mathrm{CN}$ are defined as particles larger than $3 \mathrm{~nm}$ diameter. This size corresponds to the detection limit of current instrumentation (Stolzenburg and McMurry, 1991; McMurry, 2000). $\mathrm{CCN}$ concentrations are calculated off-line from the predicted aerosol size distribution. A supersaturation of $0.2 \%$ is chosen which is typical of marine stratocumulus clouds, and corresponds to the activation of particles having a dry diameter of about $70 \mathrm{~nm}$. All aerosol concentrations are quoted at standard temperature and pressure (STP, $273 \mathrm{~K}$ and $1 \mathrm{~atm}$ ).

\section{Limitations of this study}

In this paper we restrict our analysis of microphysical uncertainties to sulfate and sea salt aerosols, which is the simplest aerosol system involving primary and secondary particles. We take this approach primarily because sensitivity studies have a high computational cost, but also because sulfate aerosols have been the most studied aerosol type in previous climate model simulations. In these earlier simulations, sulfate aerosol was sometimes the only aerosol type included or it was simulated alongside other aerosol types such as black carbon, dust and, more recently, organic carbon (Houghton et al., 2001). However, until very recently, the different aerosol types were treated as non-interacting. Our simulations, while more complete in their treatment of microphysical processes, also implicitly assume that sulfate and sea salt aerosol can be treated as being independent of other aerosol types. We stress that our conclusions regarding the sensitivity of $\mathrm{CN}$ and $\mathrm{CCN}$ concentrations to uncertain microphysical parameters apply to a subset of the total atmospheric aerosol. 


\section{The effect of different microphysical processes}

Figure 1 shows how different microphysical processes influence the modelled size distribution in the North Atlantic MBL. The effect of each process in shaping the distribution has been examined by removing one microphysical process at a time. Individual microphysical processes were switched off for 8 days and then the simulated distribution compared to the baseline distribution where all processes were included.

Without in-cloud oxidation the separate accumulation mode and Aitken mode in the MBL distribution disappear, being replaced by one broad sub-micrometer mode similar to that simulated in the free troposphere. This modelled effect supports the idea that in-cloud oxidation of $\mathrm{SO}_{2}$ is responsible for the MBL sub-micrometer bimodal distribution (Hoppel et al., 1986).

Without coagulation there is a large increase in the number of small particles and the mean diameter of the Aitken mode is shifted to smaller sizes. Coagulation removes small particles (which have high mobility and high rates of diffusion so they coagulate rapidly) but has little influence on larger particles (that have slower rates of diffusion).

Condensation of $\mathrm{H}_{2} \mathrm{SO}_{4}$ onto the existing particles reduces the concentration of gas phase $\mathrm{H}_{2} \mathrm{SO}_{4}$. With condensation switched off gas phase $\mathrm{H}_{2} \mathrm{SO}_{4}$ concentrations build up and additional nucleation occurs. This causes an increase in the concentration of small particles in the MBL and a reduction in the size of the Aitken mode. Additionally, the concentration of accumulation mode particles is reduced while their mean diameter is increased. Lack of condensational growth means fewer particles reach the diameter required for activation into cloud droplets. Fewer particles add mass though in-cloud oxidation resulting in the lower accumulation mode number. However, in-cloud oxidation is often $\mathrm{H}_{2} \mathrm{O}_{2}$ limited and so when fewer particles are activated these particles may grow to larger sizes.

Switching off particle wet removal processes causes an increase in the concentration of aerosols larger than about $100 \mathrm{~nm}$ diameter. In particular, the number of particles in the accumulation mode is greatly increased. This has the effect of increasing the surface area of the aerosol distribution. This increased surface area causes greater condensation of gaseous $\mathrm{H}_{2} \mathrm{SO}_{4}$ onto the particle distribution and less new particle formation. The number of small particles (with dry diameter less than about $40 \mathrm{~nm}$ ) is lower without wet removal processes.

Switching off sea spray emissions causes a large reduction in the number of particles larger than about $200 \mathrm{~nm}$ dry diameter. This demonstrates in a simple way the division between particles comprised mainly of sulfate and those comprised mainly of sea spray. The size distribution of particles smaller than $200 \mathrm{~nm}$ is virtually unchanged. Switching off sea salt emissions reduces particle surface area in the MBL but has little effect on surface area in the UT, which is where binary $\mathrm{H}_{2} \mathrm{SO}_{4}-\mathrm{H}_{2} \mathrm{O}$ nucleation predominately occurs in our model

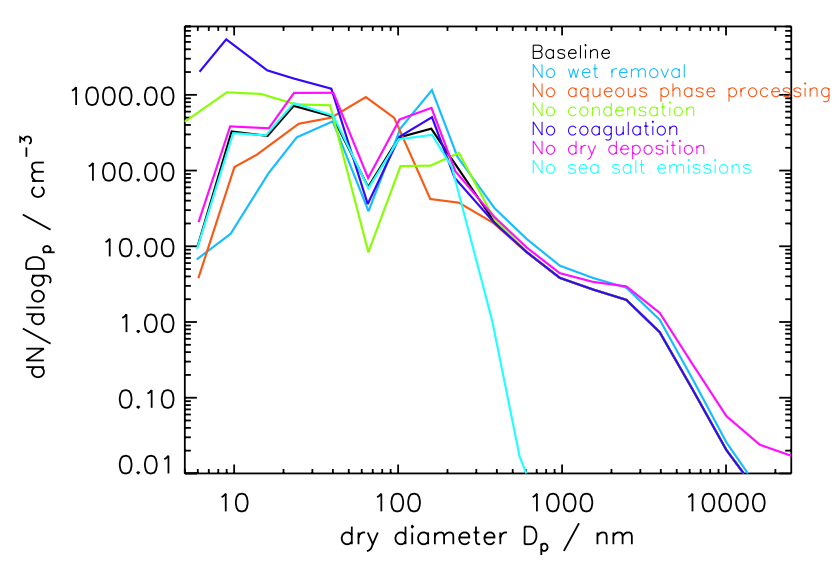

Fig. 1. Comparison of twenty four hour average number-size distributions for the North Atlantic MBL during December 1995 with all microphysical processes included and when one microphysical process at a time has been switched off for the last eight days of the model run.

(in contrast to the effect of wet scavenging, which affects particle surface areas right through the FT). Nucleation rates are therefore not greatly affected and the number of particles entraining from the UT is virtually unchanged. This effect is studied in greater detail in Sect. 5.6 where the model sensitivity to the emission strength of sea spray is explored.

Switching off turbulent dry deposition causes an increase in the number of simulated particles throughout the aerosol size distribution, but with limited impact to accumulation mode particles demonstrating a good representation of sizeresolved deposition. Dry deposition occurs only at the surface and as for changes in sea spray emissions only changes surface area in the MBL and not in the UT where new particle production occurs. Therefore, switching off dry deposition does not cause the reduction in new UT particle formation and the decrease in MBL Aitken mode particle that is observed for wet deposition.

\section{The effect on global aerosol of uncertainties in micro- physics and emissions}

It is important to understand how robust the simulated aerosol properties are, given often quite large uncertainties in the rates of microphysical processes. In this section we examine the effect of uncertainties in the sulfuric acid aerosol nucleation rate, the condensation rate of gaseous $\mathrm{H}_{2} \mathrm{SO}_{4}$ and the size of the nucleation cluster. We also examine the effect of changing the activation radius for cloud drop formation for aqueous $\mathrm{SO}_{2}$ oxidation and in-cloud nucleation scavenging. The effects of these microphysical uncertainties are then compared with the effects of uncertainties in the emission rates of sulfur species and of sea spray particles.

To perform these sensitivity studies two global aerosol fields were compared. In the first run, the global aerosol 


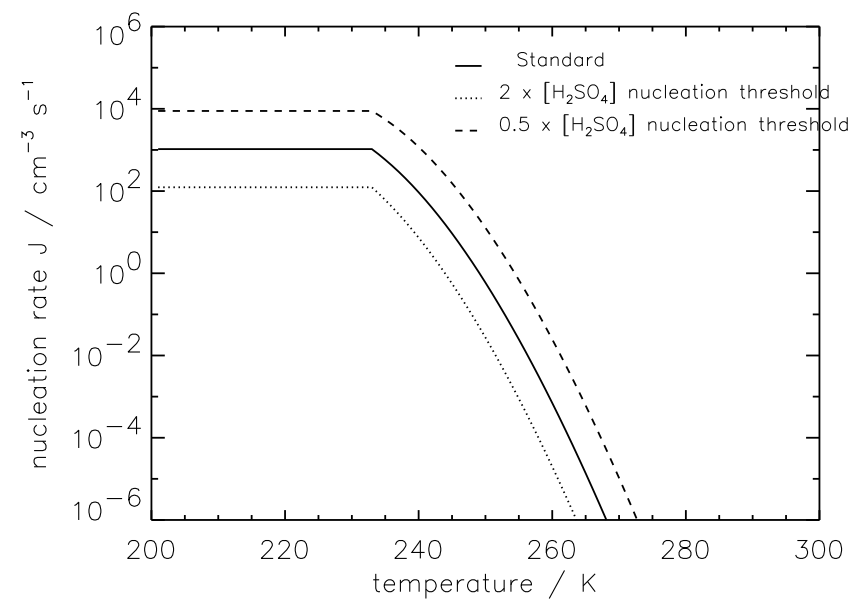

Fig. 2. Calculated nucleation rates using the Kulmala et al. (1998) paramaterisation for a fixed gas phase $\mathrm{H}_{2} \mathrm{SO}_{4}$ concentration of $3 \times 10^{7} \mathrm{~cm}^{-3}$ and relative humidity of $55 \%$. Below $233 \mathrm{~K}$ the nucleation rate is held constant.

field was calculated over a 90-day period (including a spinup from an aerosol-free atmosphere). In the second run, the model was spun up for a period of 45 days, then a particular processes were changed and the model was run for a further 45 days. Aerosol properties in these two runs are compared for the last 30 days of the 90-day model runs. Comparisons with model runs over longer time periods showed that this length of model run is sufficient to capture most of the change that occurred due to changes in parameterisation rates.

\subsection{Sensitivity to nucleation and condensation rates}

Accurately including a description of particle nucleation in a global model is difficult. There are significant uncertainties in the rate of nucleation and even the mechanisms that predominate in the atmosphere (e.g., Kulmala et al., 2004). Binary $\mathrm{H}_{2} \mathrm{SO}_{4}-\mathrm{H}_{2} \mathrm{O}$ nucleation has been the most studied mechanism, but there are examples where this mechanism seems unable to explain observed nucleation events (Weber et al., 1995; Kulmala et al., 2004). $\mathrm{NH}_{3}$ lowers the vapour pressure of $\mathrm{H}_{2} \mathrm{SO}_{4}$ above solution surfaces (Marti et al., 1997), and may increase nucleation rates by several orders of magnitude (Coffman and Hegg, 1995; Napari et al., 2002). Particle nucleation rates are strong nonlinear functions of temperature and precursor gas vapour pressure. Therefore sub-grid scale variations in humidity, temperature or $\mathrm{H}_{2} \mathrm{SO}_{4}$ concentration could lead to higher nucleation rates than the mean conditions would suggest. Sub-grid scale variability may occur through atmospheric mixing, waves, turbulence, convective eddies or cloud outflow (Easter and Peters, 1994; Nilsson et al., 2000; Clarke et al., 1998).

The binary $\mathrm{H}_{2} \mathrm{SO}_{4}-\mathrm{H}_{2} \mathrm{O}$ homogeneous nucleation rate, which we use here (Spracklen et al., 2005), is uncertain to within several orders of magnitude even under conditions where laboratory measurements are available (Vehkamäki et al., 2002). The most recent paramaterisations (Vehkamäki et al., 2002), while more physically realistic, do not agree better with the limited laboratory measurements than earlier simpler schemes (Kulmala et al., 1998). Nucleation rates below the temperature limit of observations $(236 \mathrm{~K})$ may be even less reliable. Other nucleation mechanisms are also clearly involved in the atmosphere (Kulmala et al., 2004). Sensitivity studies involving nucleation rates are therefore likely to be fairly conservative. In this work, we use the nucleation parameterisation of Kulmala et al. (1998), which is valid down to $233 \mathrm{~K}$. Below this temperature we use the rate at $233 \mathrm{~K}$. Figure 2 shows how the rate we use depends on temperature and humidity for a fixed realistic gas phase $\mathrm{H}_{2} \mathrm{SO}_{4}$ concentration of $3 \times 10^{7} \mathrm{~cm}^{-3}$. Our sensitivity studies then explore how important variations in the rate of nucleation are likely to be for aerosol distributions. Such sensitivity tests provide a reasonable measure of how the global aerosol depends on the binary homogeneous nucleation rate and suggest what improvement in parameterised rates is needed.

\subsubsection{Balance of nucleation and condensation}

Nucleation of new sulfuric acid particles and condensation of $\mathrm{H}_{2} \mathrm{SO}_{4}$ onto existing particles compete for available gas phase $\mathrm{H}_{2} \mathrm{SO}_{4}$. This competition means that uncertainties in the rates of both processes will affect the atmospheric concentration of $\mathrm{CN}$. We therefore examine the effect of uncertainties in both processes together. The results are shown in Figs. 3 and 4. GLOMAP attempts to capture the competition between nucleation and condensation by selecting a short timestep (generally about $90 \mathrm{~s}$ ) over which these processes are calculated (Spracklen et al., 2005).

Nucleation rates $(j)$ were changed by varying the $\mathrm{H}_{2} \mathrm{SO}_{4}$ nucleation threshold (the $\mathrm{H}_{2} \mathrm{SO}_{4}$ concentration at which a nucleation rate of $1 \mathrm{~cm}^{-3} \mathrm{~s}^{-1}$ is calculated) in the Kulmala et al. (1998) parametrisation. A doubling or halving of the nucleation threshold causes approximately a factor 10 change in $j$ (Fig. 2).

Condensation rates were changed by changing the accommodation coefficient, $a_{e}$, which defines the probability that a molecule of $\mathrm{H}_{2} \mathrm{SO}_{4}$ will become bound to a particle upon collision. There is considerable uncertainty in the magnitude of $a_{e}$. Van Dingenen and Raes (1991) report values of $a_{e}$ in the range of 0.02 to 0.1 . The theoretical studies of Clement et al. (1996) and the field measurements of Weber et al. (1995) report values of $a_{e}$ close to unity. Pöschl et al. (1998) experimentally determined $a_{e}$ at $303 \mathrm{~K}$ with a lower limit of 0.43 and a best fit value of 0.65 . Jefferson et al. (1997) measured $\mathrm{H}_{2} \mathrm{SO}_{4}$ uptake onto $\left(\mathrm{NH}_{4}\right)_{2} \mathrm{SO}_{4}$ aerosol and reported values of $0.73 \pm 0.21$ and onto $\mathrm{NaCl}$ aerosol of $0.79 \pm 0.23$. Models also use a wide range of values; Pandis et al. (1994) and Russell et al. (1994) use a value of 0.02; Raes (1995), 0.3; Katoshevski et al. (1999), 1.0; Adams and 


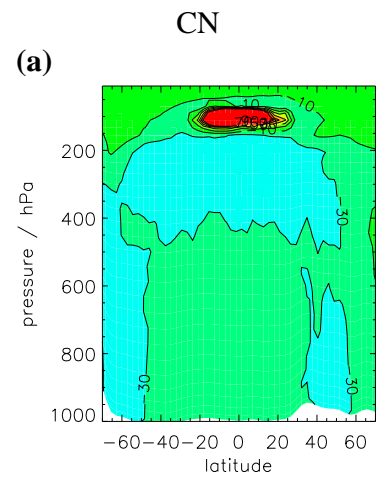

(b)

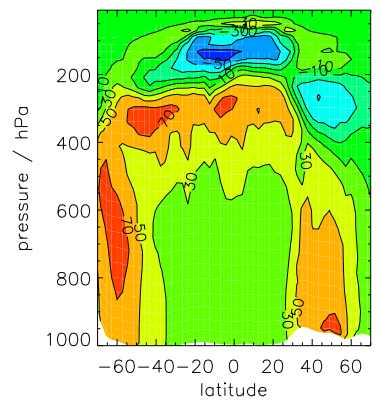

$\mathrm{CCN}$
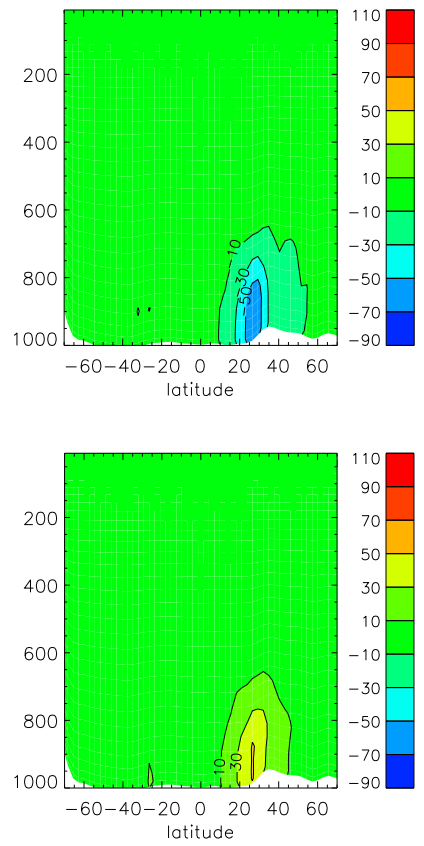

Fig. 3. Monthly mean change in zonal mean $\mathrm{CN}$ (\% change) and CCN (absolute change $\left(\mathrm{cm}^{-3}\right)$ at $0.2 \%$ supersaturation) at STP for December 1995 for (a) $\mathrm{H}_{2} \mathrm{SO}_{4}$ threshold twice that of baseline case; (b) $\mathrm{H}_{2} \mathrm{SO}_{4}$ threshold half that of baseline case. A doubling/halving of the threshold $\mathrm{H}_{2} \mathrm{SO}_{4}$ concentration for nucleation in the Kulmala et al. (1998) parameterisation causes approximately a factor 10 decrease/increase in the nucleation rate under most conditions (see Sect. 5.1.1).

Seinfeld (2002), 0.65 and Easter et al. (2004), 0.02. Laboratory and field studies have shown that the value of $a_{e}$ is reduced as a particle becomes increasingly covered in surfactants (Däumer et al., 1992). Marine air contains substantial surfactant concentrations from ocean bubble bursting which may be able to coat marine aerosol particles, thereby reducing accommodation coefficients.

Figures 3 and 4 show that increasing $j$ (or decreasing $a_{e}$ ) causes an increase in $\mathrm{CN}$ concentrations below about 200 $400 \mathrm{hPa}$ and a decrease in $\mathrm{CN}$ at higher levels. In the upper troposphere the pattern of response to increasing $j$ or decreasing $a_{e}$ is similar, with changes $>50 \%$. These fractional changes in $\mathrm{CN}$ concentration appear to be counterintuitive as one might expect an increase in $\mathrm{CN}$ concentration in response to an increased nucleation rate. Figure 5 shows altitude profiles for a remote marine situation and a polluted continental situation and gives a rather different perspective on how $\mathrm{CN}$ concentrations change. In both locations, changing $j$ and $a_{e}$ changes the altitude in the UT at which the maximum $\mathrm{CN}$ concentration occurs (a shift of about $1.5 \mathrm{~km}$ for a factor 10 change in $j$ or $3 \mathrm{~km}$ for a change in $a_{e}$ from 1.0 to 0.3 ), while the shape of the $\mathrm{CN}$ profile is essentially pre-
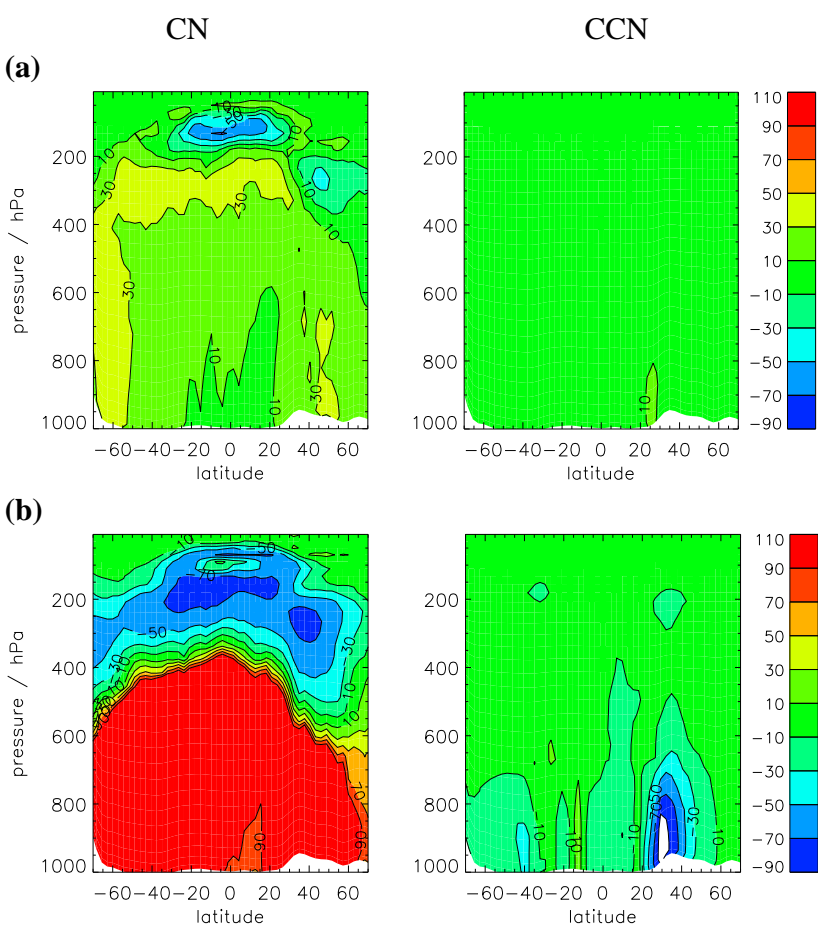

Fig. 4. Monthly mean change in zonal mean $\mathrm{CN}$ (percentage change) and $\mathrm{CCN}$ (absolute change $\left(\mathrm{cm}^{-3}\right)$ at $0.2 \%$ supersaturation) at STP for December 1995 for accommodation coefficients of (a) $\mathrm{a}_{e}=0.65$; (b) $a_{e}=0.02$. Baseline model runs use $a_{e}=1.0$

served. Increasing $j$ (or decreasing $a_{e}$ ) decreases the altitude of the $\mathrm{CN}$ maximum, whereas decreasing $j$ (or increasing $a_{e}$ ) increases the altitude of the $\mathrm{CN}$ maximum. This shift in altitude of the $\mathrm{CN}$ layer has important consequences for comparing model CN number against UT CN measurements. Due to the strong vertical gradients of particle number concentrations in the UT, model error in the altitude of the $\mathrm{CN}$ maxima will cause large errors in the predicted $\mathrm{CN}$ concentrations at any altitude.

Figure 5 also shows changes in the vertical profile of the total particle concentration (including particles smaller than $3 \mathrm{~nm}$ diameter). These look very different from the changes in $\mathrm{CN}$, with increasing nucleation rates now causing increases in the total particle concentration and no change in the altitude at which the maximum concentration occurs. Reducing the $\mathrm{H}_{2} \mathrm{SO}_{4}$ nucleation threshold increases the rate of production of nucleation clusters, which, at any altitude, gives rise to higher concentrations of nucleation clusters and hence also total aerosol. The concentration of $\mathrm{CN}$ depends on the number of nucleation clusters that survive coagulational scavenging up to $3 \mathrm{~nm}$ diameter. The number of $\mathrm{CN}$ therefore depends on the competition between nucleation and condensation for available $\mathrm{H}_{2} \mathrm{SO}_{4}$. As altitude increases, temperature decreases causing the $\mathrm{H}_{2} \mathrm{SO}_{4}$ nucleation threshold to decrease. Thus at higher altitudes the gas phase $\mathrm{H}_{2} \mathrm{SO}_{4}$ concentrations, and hence condensation rates, tend to be lower, 
(a) Tropical Pacific $\left(10^{\circ} \mathrm{N}-10^{\circ} \mathrm{S}, 210-270^{\circ} \mathrm{E}\right)$

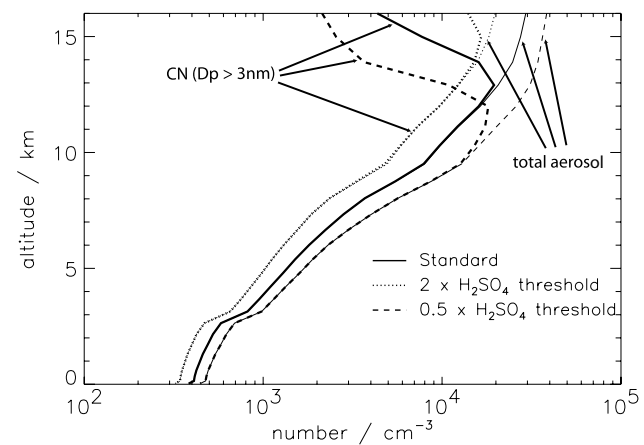

(b) Northern Europe $\left(45-60^{\circ} \mathrm{N}, 5-25^{\circ} \mathrm{E}\right)$

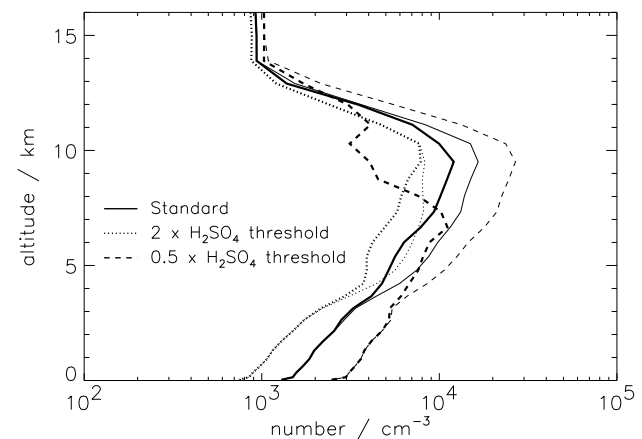

(c) Tropical Pacific $\left(10^{\circ} \mathrm{N}-10^{\circ} \mathrm{S}, 210-270^{\circ} \mathrm{E}\right)$

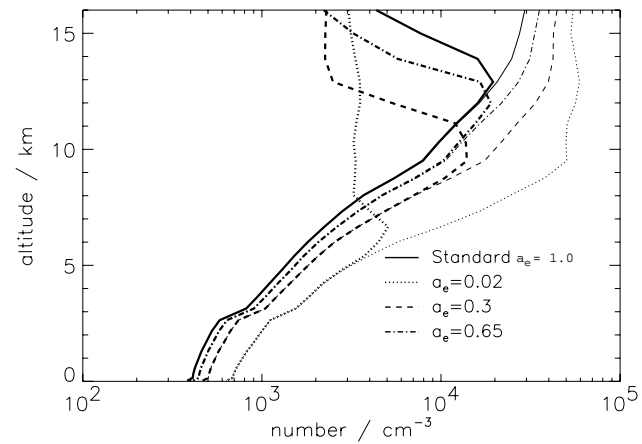

(d) Northern Europe $\left(45-60^{\circ} \mathrm{N}, 5-25^{\circ} \mathrm{E}\right)$

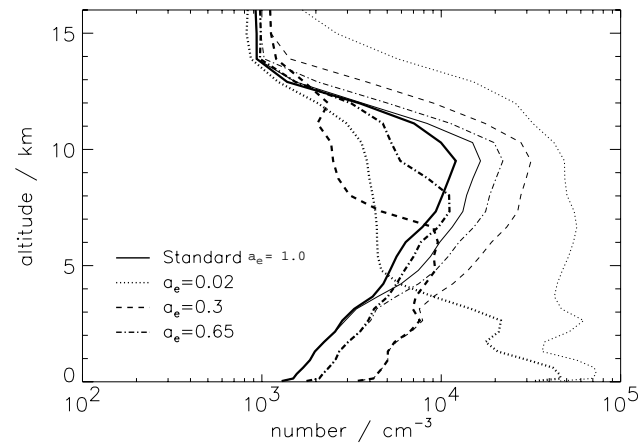

Fig. 5. Monthly mean vertical profiles for December 1995 for changes in nucleation and condensation rate. Number concentration (at STP) are shown for particles with dry diameter greater than $3 \mathrm{~nm}$ (thick lines) and all particles including nucleation clusters less than $3 \mathrm{~nm}$ diameter (thin lines). (a)

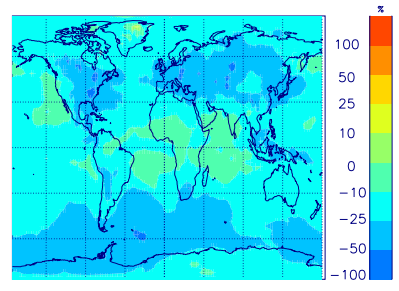

(b)

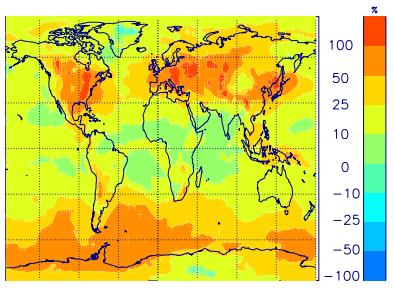

Fig. 6. Monthly mean percentage change in surface mean $\mathrm{CN}$ concentrations for December 1995. (a) $\mathrm{H}_{2} \mathrm{SO}_{4}$ threshold twice that of baseline case; (b) $\mathrm{H}_{2} \mathrm{SO}_{4}$ threshold half that of baseline case.

which reduces cluster growth rates and increases the fraction of clusters that are coagulationally scavenged before reaching $3 \mathrm{~nm}$. The altitude of the $\mathrm{CN}$ maximum occurs where the combination of the nucleation and condensation rates gives rise to the highest $\mathrm{CN}$ number. As $j$ increases (or $a_{e}$ decreases) the altitude at which this occurs decreases causing the decrease in the altitude of the $\mathrm{CN}$ maximum.

Below the UT the response of $\mathrm{CN}$ concentrations to changes in $j$ and $a_{e}$ depends on the abundance of sulfur species. Over polluted regions (Fig. $5 \mathrm{~b}$ and d) $\mathrm{CN}$ concentrations in the lower atmosphere change by more than a factor of 2 when $j$ and $a_{e}$ are changed. In polluted continental regions, where more gas phase $\mathrm{H}_{2} \mathrm{SO}_{4}$ is present, particle growth rates are faster and increased nucleation rates leads to higher BL number concentrations as more nucleation mode particles grow fast enough to survive coagulational scavenging. The effect of changes in $a_{e}$ is particularly marked in the polluted lower troposphere (Fig. 5d), where $\mathrm{CN}$ concentrations increase by up to a factor of 20 when $a_{e}$ is reduced from 1.0 to 0.02 . Reducing $a_{e}$ this much allows BL gas phase $\mathrm{H}_{2} \mathrm{SO}_{4}$ concentrations to build up sufficiently to allow BL binary $\mathrm{H}_{2} \mathrm{SO}_{4}-\mathrm{H}_{2} \mathrm{O}$ nucleation to occur. In contrast, tropical remote MBL locations (Fig. 5a and c) typically show less than a $10 \%$ change in $\mathrm{CN}$ concentrations when $j$ changes by an order of magnitude. In such clean locations the low $\mathrm{H}_{2} \mathrm{SO}_{4}$ concentrations ensure that nucleation occurs almost exclusively in the UT.

Below the UT, the response of $\mathrm{CN}$ to changes in $j$ and $a_{e}$ is also dependent on the temperature. Low FT temperatures allow nucleation to occur nearer the surface. Figure 6 shows that changes in $\mathrm{CN}$ in the Southern Ocean BL $\left(40^{\circ}-60^{\circ} \mathrm{S}\right)$ are in excess of $100 \%$ when $j$ changes by a factor 10 , but are considerably less in the tropics.

Changing nucleation rates by an order of magnitude causes about a 6-9\% change in global mean MBL sulfate and sea salt derived CCN concentrations. Reducing the accommodation coefficient from 1.0 to 0.3 causes little effect on global mean CCN concentrations. However, reducing condensation rates further (by reducing $a_{e}$ to 0.02 ) causes about a $25 \%$ reduction in global mean MBL sea salt and sulfate CCN concentrations. 
Conclusions regarding the sensitivity of $\mathrm{CN}$ and $\mathrm{CCN}$ concentrations to changes in nucleation and condensation rates are of course restricted to simulations using a binary $\mathrm{H}_{2} \mathrm{SO}_{4}$ $\mathrm{H}_{2} \mathrm{O}$ homogeneous nucleation rate and with sulfate and sea salt as the only aerosol constituents. The nucleation scheme we use produces particles mostly in the cold UT and FT. Changes in BL CN therefore tend to be rather small. Observations suggest that $\mathrm{CN}$ can also be produced in the planetary boundary layer (Kulmala et al., 2004), perhaps assisted by condensation of organic vapours. It is therefore likely that these simulations underpredict the effect that changes in nucleation rate have on the $\mathrm{BL}$ aerosol distribution. In addition, our simulations will underpredict continental aerosol surface area and so are likely to underestimate the impact of uncertainty in condensation rates on aerosol properties. However, in a model in which particle formation occurs through binary homogeneous nucleation the $\mathrm{CN}$ source to the $\mathrm{BL}$ is decoupled from the surface area in the BL itself.

\subsubsection{Sensitivity to the nucleation cluster size}

The nucleation critical cluster is the smallest size above which a cluster of $\mathrm{H}_{2} \mathrm{SO}_{4}$ molecules is stable. The nucleation parametrisation of Kulmala et al. (1998) does not provide any information on the critical cluster size of the nucleating particles, although more recent parametrisations do (Vehkamäki et al., 2002). The sensitivity to the cluster size was investigated by reducing the cluster size from 100 to 10 molecules of $\mathrm{H}_{2} \mathrm{SO}_{4}$.

Reducing the critical cluster size causes a downward shift in the altitude of the $\mathrm{CN}$ maximum (by as much as $3 \mathrm{~km}$ ) and an overall reduction in the concentration (Fig. 7). However, altitude profiles of total particle number (including particles less than $3 \mathrm{~nm}$ diameter) have the same shape irrespective of the critical cluster size, with smaller critical clusters giving greater particle number at any altitude in the UT. Smaller critical clusters take longer to grow to observable sizes $(>3 \mathrm{~nm}$ diameter) where they are counted as CN. Smaller clusters are therefore subject to coagulational scavenging for a longer period of time, which causes a reduction in $\mathrm{CN}$ concentration (smaller particles also have higher mobility and therefore higher coagulational loss rates). The shift in altitude of the $\mathrm{CN}$ maximum can be explained by changes in the growth and coagulation rates with altitude for different initial cluster sizes: smaller critical clusters take longer to grow to $\mathrm{CN}$ sizes and are more likely to be coagulation scavenged by the existing particle sink rather than grow through condensation to a form a new $\mathrm{CN}$. As altitude increases, the temperature falls and gives rise to a reduced $\mathrm{H}_{2} \mathrm{SO}_{4}$ nucleation threshold. This causes reduced gas phase $\mathrm{H}_{2} \mathrm{SO}_{4}$ concentrations which in turn causes reduced condensational growth rates. Rates of coagulational scavenging are fairly stable with altitude (due to relatively stable Aitken mode concentrations) which means as altitude increases nucleation clusters are more likely to be scavenged before they can grow into $\mathrm{CN}$ (a) Tropical Pacific $\left(10^{\circ} \mathrm{N}-10^{\circ} \mathrm{S}, 210-270^{\circ} \mathrm{E}\right)$

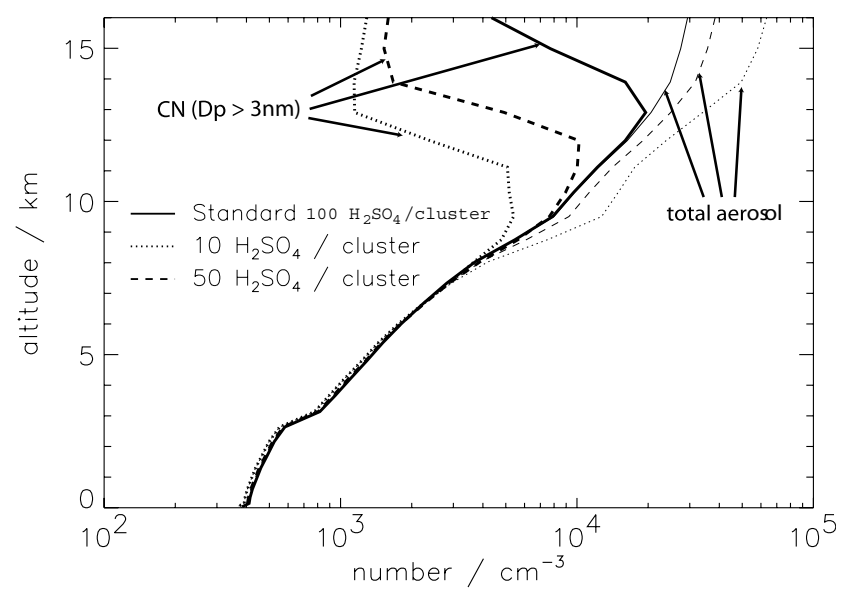

(b) Northern Europe $\left(45-60^{\circ} \mathrm{N}, 5-25^{\circ} \mathrm{E}\right)$

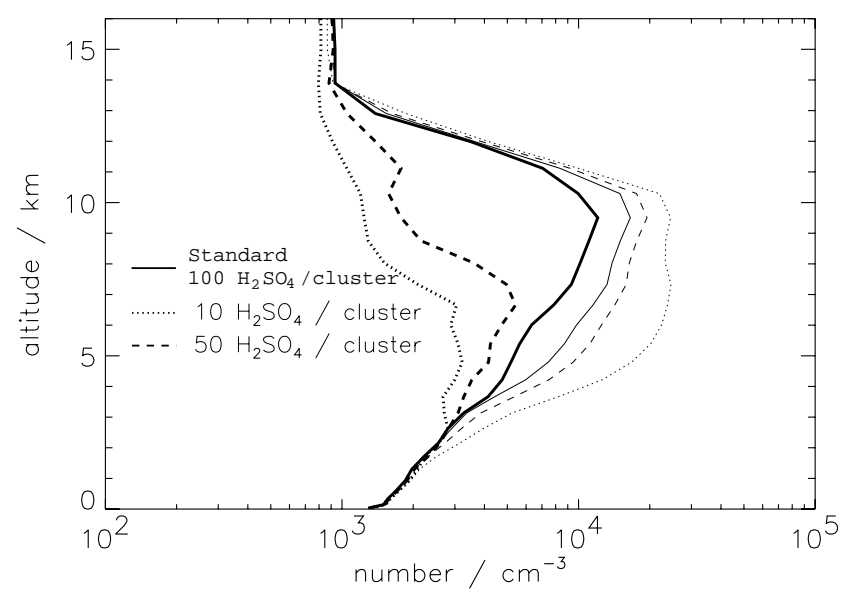

Fig. 7. Monthly mean vertical profiles during December 1995 for different $\mathrm{H}_{2} \mathrm{SO}_{4}$ nucleation cluster sizes. Number concentration (at STP) are shown for particles with dry diameter greater than $3 \mathrm{~nm}$ (thick lines) and all particles including nucleation clusters less than $3 \mathrm{~nm}$ diameter (thin lines).

sized particles. Therefore as the critical cluster size is decreased the altitude at which nucleation clusters will be more likely to grow into $\mathrm{CN}$ than be scavenged also decreases. Conclusions regarding the growth rates and survival of nucleating clusters will be dependent on the accuracy of model coagulation rates.

Global mean MBL CN concentrations change by less than $2 \%$. Global mean MBL CCN concentrations (not shown) are virtually unaffected, changing by less than $1 \%$.

\subsection{Sensitivity to aqueous phase oxidation}

In GLOMAP, aerosol particles are assumed to activate into cloud droplets when low warm-phase cloud is present and the particle diameter is greater than a preset fixed diameter (Spracklen et al., 2005). Activated particles are assumed to grow into droplets in cloudy air and subsequently support 


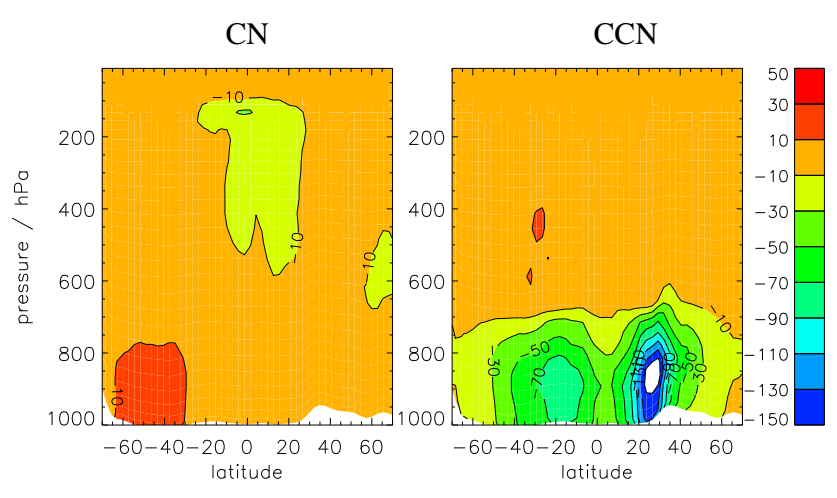

Fig. 8. Monthly mean change in zonal mean $\mathrm{CN}$ (\% change) and CCN (absolute change $\left(\mathrm{cm}^{-3}\right)$ at $0.2 \%$ supersaturation) concentrations at STP for December 1995 for an aerosol activation diameter into cloud droplets of $0.08 \mu \mathrm{m}$. Baseline activation diameter is $0.05 \mu \mathrm{m}$.

oxidation of $\mathrm{SO}_{2}$ to sulfate, which then remains on the particles as the air subsequently passes into clear air. In the baseline model runs, aerosol particles are assumed to activate at an equivalent dry diameter of $0.05 \mu \mathrm{m}$. Figure 8 shows the sensitivity of simulated aerosol distributions to a change in this activation diameter.

The changes in CCN concentration shown in Fig. 8 are calculated at $0.2 \%$ supersaturation. The activation diameter used during the model simulation was fixed at $0.05 \mu \mathrm{m}$ in the baseline run and $0.08 \mu \mathrm{m}$ (corresponding to $0.18 \%$ supersaturation) in the sensitivity run. In the atmosphere the activation diameter will vary greatly from one cloud to another and from region to region driven partly by variations in updraught velocity. In any model sensitivity run the activation diameter and hence cloud supersaturation is fixed. Effectively, we are simulating repeated aerosol activation and in-cloud oxidation at a fixed high or low supersaturation and then examining the effect of such events on the $\mathrm{CCN}$ abundance at some average supersaturation of $0.2 \%$.

Increasing the activation diameter from 0.05 to $0.08 \mu \mathrm{m}$ reduces global mean MBL CCN $(0.2 \%)$ concentrations by around $50 \%$. Using a smaller activation diameter in the model allows a greater proportion of the particles to grow rapidly through aqueous phase oxidation of $\mathrm{SO}_{2}$ while the particles exist as cloud droplets. This growth of small particles leads to a greater concentration of particles that can be activated at more moderate supersaturations of $0.2 \%$.

Figure 9a shows how a change in the activation diameter affects the simulated number-size distribution in the subtropical MBL. Changes in the size distribution are apparent between $10 \mathrm{~nm}$ and about $1 \mu \mathrm{m}$. Above about $1 \mu \mathrm{m}$ the number-size distribution is dominated by sea salt emission and deposition fluxes. Increasing the size of the activation diameter for in-cloud oxidation causes an increase in the mean diameter of the Aitken mode from $\sim 25 \mathrm{~nm}$ to around $\sim 60 \mathrm{~nm}$. Increasing the activation diameter also reduces the (a)

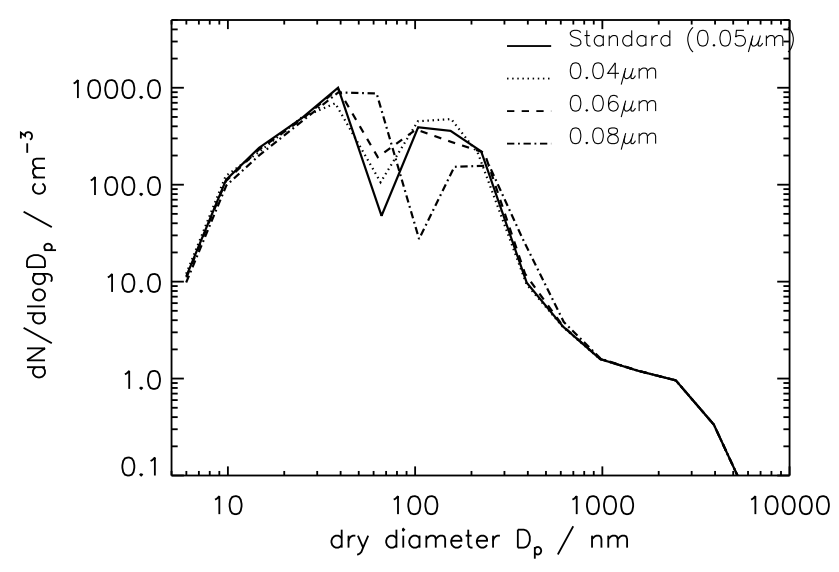

(b)

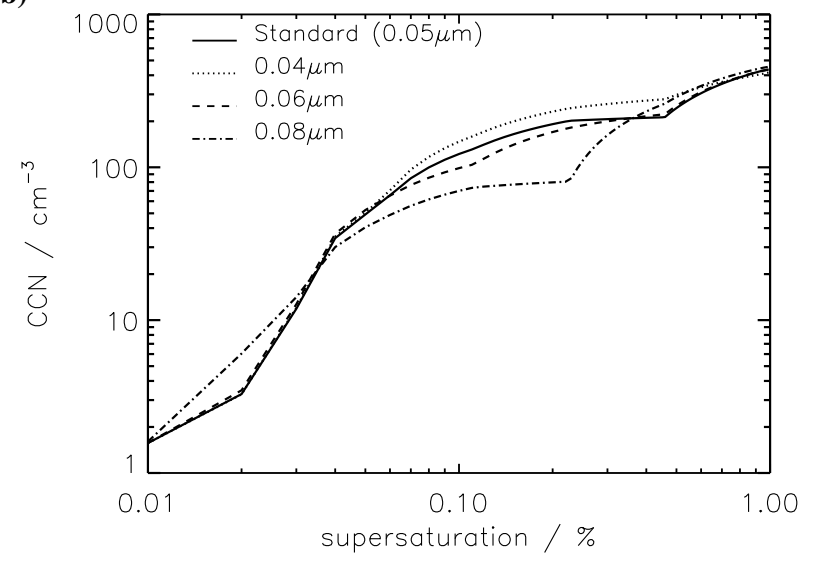

Fig. 9. Monthly mean simulated aerosol distributions in the tropical Pacific MBL $\left(10^{\circ} \mathrm{N}-10^{\circ} \mathrm{S}, 210-270^{\circ} \mathrm{E}\right)$ for December 1995 with different activation diameters for aqueous phase oxidation. (a) Number-size distribution; (b) CCN spectrum.

number and increases the mean diameter of the accumulation mode. In many cases aqueous phase oxidation will be $\mathrm{H}_{2} \mathrm{O}_{2}$ limited. At larger activation diameters the fewer particles that are large enough to activate will share the available $\mathrm{H}_{2} \mathrm{O}_{2}$. These fewer activated particles will therefore tend to add more mass and grow to larger sizes.

These results can also be shown as a change in the CCN spectrum. Measurements made using $\mathrm{CCN}$ counters give the number concentration of $\mathrm{CCN}$ active at particular supersaturations (Gras, 1995; Ayers and Gillett, 2000). Figure 9b shows the simulated CCN number concentration at supersaturations between 0 and $1 \%$ for the 4 model runs with different particle activation diameters. The $\mathrm{CCN}$ number concentration is calculated for each supersaturation using Kohler theory, assuming that particles larger than the critical diameter instantly grow into cloud droplets. As the supersaturation is increased from 0 to $1 \%$ the number concentration of activated particles increases as the diameter of activation decreases. At very low supersaturations only large sea salt 
particles will activate and the number of $\mathrm{CCN}$ are identical for all the different activation diameters. At slightly higher supersaturations $(0.01-0.04 \%)$ larger activation diameters result in greater CCN number due to the larger mean size of the simulated accumulation mode. At slightly higher supersaturations (between about 0.06 and $0.4 \%$ ) the number of $\mathrm{CCN}$ is greater for smaller model activation diameters. Smaller activation diameters mean that a greater subset of the particle population in activated and adds mass through aqueous-phase oxidation. However, as the supersaturation is raised further (to $0.4-1 \%$ ) the $\mathrm{CCN}$ concentrations are slightly larger for small activation diameters. Smaller activations diameters give an increase in the mean diameter of the simulated Aitken mode, which are then activated as the supersaturation increases.

Finally, it is worth noting that changing the diameter of activation has little effect on global mean $\mathrm{CN}$ concentrations, which change by about $1-2 \%$ when the diameter of activation changes from 0.04 to $0.08 \mu \mathrm{m}$.

\subsection{Sensitivity to nucleation scavenging}

Loss of aerosol due to nucleation, or in-cloud, scavenging is a complex process that can be viewed as occurring over two separate stages. In the first stage (cloud formation), those aerosol with radii greater that a certain critical radius grow rapidly by diffusion and condensation to form a spectrum of cloud droplets. Of these newly formed droplets, only those with radii greater than $20 \mu \mathrm{m}$ will undergo efficient collisioncoalescence to produce raindrops (Rogers and Yau, 1989).

In GLOMAP, aerosol with a dry diameter greater than $0.05 \mu \mathrm{m}$ are assumed able to activate to form cloud drops. During rain formation, the largest of these cloud drops will coalesce most efficiently and will be preferentially lost from the cloud. Following the assumption that the largest aerosol will form the largest cloud droplets (Flossmann, 1991), it can be assumed that in-cloud scavenging will preferentially remove the largest of the activated aerosol. An effective scavenging diameter of $0.206 \mu \mathrm{m}$ is chosen above which nucleation scavenging may occur in the model. This value is intermediate between the values used by Adams and Seinfeld (2003) $(0.03 \mu \mathrm{m}$ and $0.082 \mu \mathrm{m}$ for convective and stratiform clouds respectively) and that used by Capaldo et al. (1999) $(0.250 \mu \mathrm{m})$. The assumption of one globally uniform scavenging diameter limits the extent to which the model can capture the effect of different cloud types, however this is difficult to rectify without the inclusion of a detailed cloud microphyics model. Scavenging is scaled to the rate of conversion of condensate to rain drops, this value is typically close to $100 \%$.

Model sensitivity to the magnitude of the scavenging diameter is investigated by reducing it to $0.1 \mu \mathrm{m}$. This causes an increase in $\mathrm{CN}$ concentrations (between the surface and $20 \mathrm{hPa}$ ) of up to $100 \%$ and a decrease in $\mathrm{CCN}$ concentrations (between the surface and $200 \mathrm{hPa}$ ) of up to $50 \mathrm{~cm}^{-3}$. CN

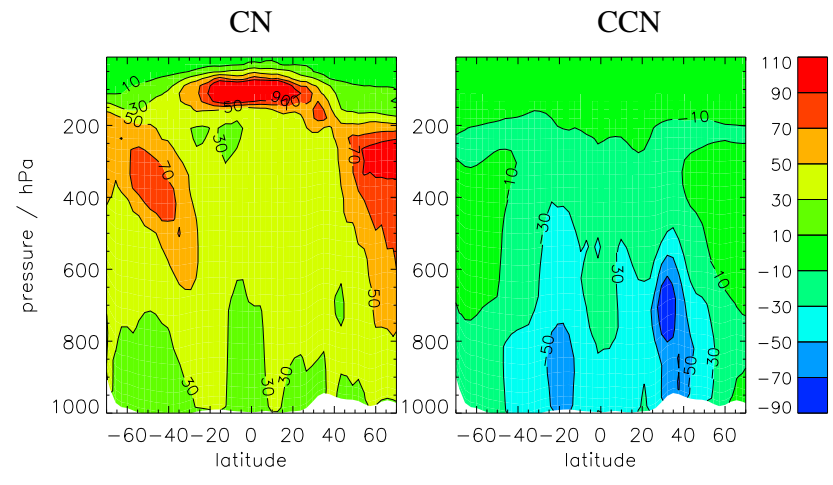

Fig. 10. Monthly mean change in zonal mean $\mathrm{CN}$ (\% change) and $\mathrm{CCN}$ (absolute change $\left(\mathrm{cm}^{-3}\right)$ at $0.2 \%$ supersaturation) concentrations at STP for activation diameters into cloud droplets for nucleation scavenging of $0.1 \mu \mathrm{m}$. Baseline activation diameter is $0.206 \mu \mathrm{m}$.

concentrations are most affected in the UT whereas CCN concentrations are most affected in the BL. Reducing the scavenging diameter allows more particles to be scavenged, thus more aerosol mass is removed per precipitation event. This reduces aerosol surface area and promotes the nucleation of new particles. Rates of coagulational scavenging also decrease, allowing more nucleation clusters to survive and grow into $\mathrm{CN}$.

\subsection{Sensitivity to particulate sulfate emissions}

Here we examine the effect of a small emission of anthropogenic sulfur species in the form of particulates, as has been observed downwind of power plants.

Electricity generation from power plants accounts for a large proportion of anthropogenic emissions of $\mathrm{SO}_{2}$. In the United States $69 \%$ of anthropogenic $\mathrm{SO}_{2}$ is emitted by coalfired power plants (EPA, 2000). Emissions of sulfur at the power plant stack are thought to be primarily gaseous $\mathrm{SO}_{2}$, due to high exhaust temperatures and electrostatic precipitators which remove primary particles (Brock et al., 2002). However, within hours of emission, power plant plumes may experience rapid gas to particle conversion. Brock et al. (2002) measured enhanced particle number concentrations (in the order of $1 \times 10^{4}$ to $1 \times 10^{5} \mathrm{~cm}^{-3}$ ) at distances of 20 to $100 \mathrm{~km}$ downwind of coal fired power plants in the United States.

Gas to particle conversion may occur on spatial scales (10s of $\mathrm{km}$ ) that are not resolved by global models (with grid squares of $100 \mathrm{~km}$ or more). In the model, if $\mathrm{SO}_{2}$ is simply mixed into a model grid box, the average grid box concentration that is calculated will be an underestimate of the concentrations that are present in the power plant plume before it mixes with the larger scale air masses. If the timescale for oxidation of $\mathrm{SO}_{2}$ into $\mathrm{H}_{2} \mathrm{SO}_{4}$ is fast compared to the mixing timescale this may lead to an underprediction of the 
(a)
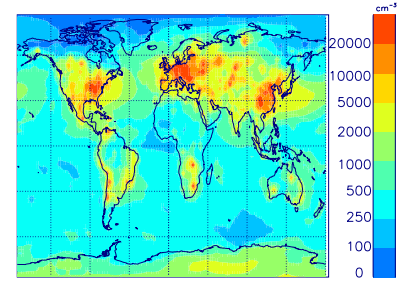

(a)

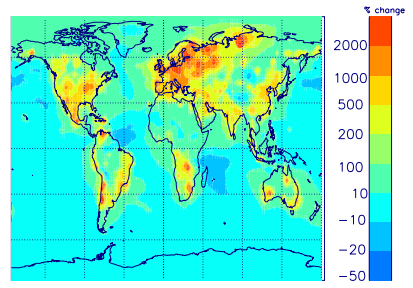

(b)

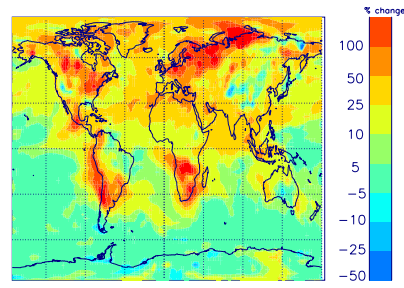

Fig. 11. Monthly mean surface (a) $\mathrm{CN}$ and (b) $\mathrm{CCN}(0.2 \%$ supersaturation) concentrations for December 1995 with $3 \%$ of $\mathrm{SO}_{2}$ as particulate emissions.

concentration of gaseous $\mathrm{H}_{2} \mathrm{SO}_{4}$ in the plume. In general the average grid box concentrations will not result in any gas to particle conversion. However, the strongly non-linear relationship between $\mathrm{H}_{2} \mathrm{SO}_{4}$ concentration and nucleation rate may mean that substantial nucleation occurs in the plume. The model, which calculates nucleation from average grid point values, will underestimate new particle formation that occurs in the power plant plume.

To account for this sub-grid scale particle formation occurring in the plume, a fraction of the total $\mathrm{SO}_{2}$ emissions into a grid box is assumed to be emitted as particulate sulfate. Estimates of the amount of the emitted $\mathrm{SO}_{2}$ that forms particulate sulfate in the power plant plume range from less than 1\% (Dietz and Wieser, 1983; Eliassen and Saltbones, 1983) to up to 5\% (Saeger et al., 1989; EMEP, 1989). Recently, some global aerosol models have attempted to include these direct anthropogenic particulate emissions of sulfate (Gong et al., 2003; Adams and Seinfeld, 2002, 2003). Adams and Seinfeld (2003) reported that neglecting emissions of particulates causes an underprediction of $\mathrm{CCN}$ number. Particulate emissions were shown to be more effective at producing $\mathrm{CCN}$ than an equivalent amount of gaseous $\mathrm{SO}_{2}$ emissions.

Here we assume that a $1-5 \%$ emission of $\mathrm{SO}_{2}$ as particulates is used as an estimate solely for sub-grid nucleation of sulfate in power plant plumes. It has been suggested that this method could also be used as a simple surrogate for primary carbonaceous emissions (Adams and Seinfeld, 2003). However, other models include carbonaceous aerosol in addition to emissions of primary sulfate. For example, the ECHAM5HAM model includes $2.5 \%$ of $\mathrm{SO}_{2}$ as primary sulfate in addition to emissions of primary carbonaceous emissions (Stier et al., 2005). These different approaches will result in different simulated $\mathrm{CN}$ and $\mathrm{CCN}$ concentrations. Our estimates of $\mathrm{CCN}$ sensitivity need to be repeated in a model with a more complete range of aerosol types.

The effect of including direct particulate emissions in GLOMAP is investigated by comparing model simulations in which all anthropogenic sulfur emissions are assumed to be $\mathrm{SO}_{2}$ with simulations in which a fraction is assumed to be particulate sulfate. The fraction of $\mathrm{SO}_{2}$ that is allowed to nucleate in the emission plume is changed from 1 to $5 \%$ by
Fig. 12. Monthly mean percentage change in surface (a) $\mathrm{CN}$ and (b) $\mathrm{CCN}\left(0.2 \%\right.$ supersaturation) concentrations for $3 \% \mathrm{SO}_{2}$ emitted as particulate sulfate compared to model run with $100 \%$ of emissions as $\mathrm{SO}_{2}$.

mass of total $\mathrm{SO}_{2}$ emissions. Primary particles are assumed to be formed as two lognormal modes with geometric mean diameters of 10 and $70 \mathrm{~nm}$ and standard deviations of 1.6 and 2.0, respectively (Whitby, 1978). Fifteen percent by mass of the primary particles is assumed to be emitted in the small mode and the remainder in the large mode (Binkowski and Shankar, 1995).

Figures 11 and 12 show changes in BL CN and CCN for different fractions of particulate sulfate emission and Fig. 13 shows zonal mean changes. Without direct particulate emissions, surface $\mathrm{CN}$ concentrations over polluted regions are typically $1000-2000 \mathrm{~cm}^{-3}$, which is less than typically observed values of $2500-10000 \mathrm{~cm}^{-3}$ (Raes et al., 2000). When primary emissions are included, total number concentrations over polluted areas increase to $2000-10000 \mathrm{~cm}^{-3}$, which is comparable with measurements. However, in polluted regions carbonaceous aerosol would be expected to contribute significantly to $\mathrm{CN}$ number. Including $3 \%$ of $\mathrm{SO}_{2}$ as particulates (with the diameter and standard deviation assumed here) may cause an overestimate of the contribution of sulfate aerosol to total CN. Small changes in the assumptions about the size of primary sulfate emissions will cause large changes in simulated aerosol number. Including carbonaceous aerosol in the model will be required to test the contributions of primary sulfate and carbonaceous aerosol to total CN. It is likely that to accurately predict the contribution of carbonaceous aerosol to tropospheric $\mathrm{CCN}$ will require more extensive observations regarding the size distribution of primary carbonaceous emissions.

Over polluted regions, including particulate emissions increases BL CN concentrations by up to a factor of 10 or more. Surface CN number is increased over a large proportion of the North Atlantic. In comparison, over remote marine and continental regions $\mathrm{BL} \mathrm{CN}$ concentrations remain relatively unchanged (changing by between $10 \%$ and $-10 \%$ ).

Over polluted regions, $\mathrm{CCN}$ concentrations increase from between $500-1000 \mathrm{~cm}^{-3}$ to $1000-5000 \mathrm{~cm}^{-3}$. Again there is no simulated effect over remote marine and continental areas. At altitudes above about $400 \mathrm{hPa} \mathrm{CCN}$ number is relatively unchanged. 


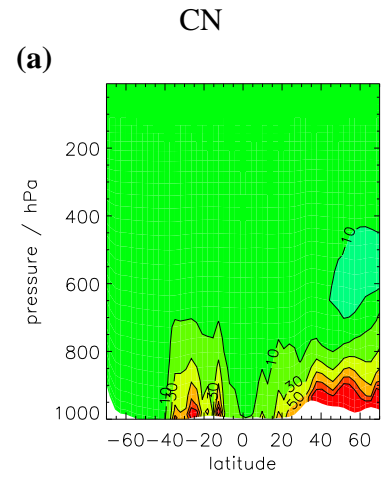

(b)

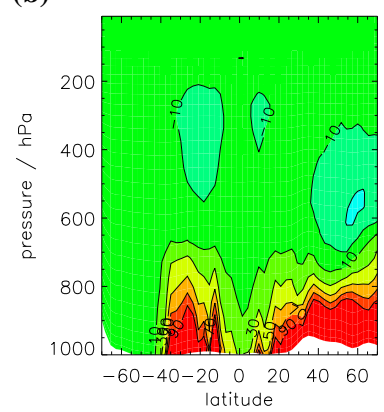

$\mathrm{CCN}$
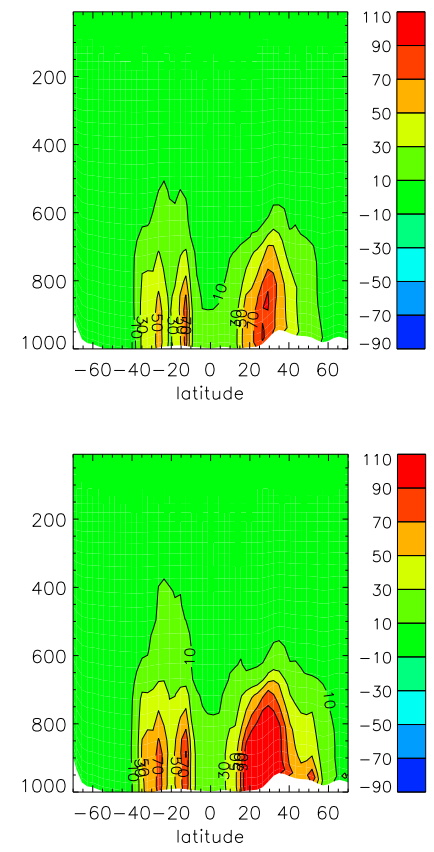

Fig. 13. Monthly mean change in zonal mean $\mathrm{CN}$ (\% change) and $\mathrm{CCN}$ (absolute change $\mathrm{cm}^{-3}$ at $0.2 \%$ supersaturation) concentrations at STP for December 1995. (a) 1\% direct particulate emissions; (b) 3\% direct particulate emission.

\subsection{Sensitivity to sulfur species emission rates}

The sensitivity of the simulated aerosol distributions to uncertainty in the emissions database is studied and compared to the sensitivity to uncertainties in the driving microphysical processes.

GLOMAP uses the Global Emissions Inventory Activity (GEIA) for the emissions of anthropogenic $\mathrm{SO}_{2}$. Benkovitz et al. (1996) estimates the uncertainty of the GEIA emissions database. Uncertainty is lowest for regions where detailed inventories are available (such as in the US and Europe) and highest where no inventories are available such as over South America and Africa. Uncertainty in regional inventories in Europe (Tuovinen et al., 1994) and the US (Saeger et al., 1989) has been estimated as $25 \%$.

GLOMAP uses the DMS sea-surface concentration database of Kettle et al. (1999) and the sea-air transfer rate from Liss and Merlivat (1986). Uncertainty in the emission rate of DMS is a combination of the uncertainty in DMS sea surface concentrations and the uncertainty in the sea-air transfer rate. The Kettle et al. (1999) database was created using a model that interpolates to a $1^{\circ} \times 1^{\circ}$ grid from more than 15000 point DMS measurements. The inaccuracy in the database values at any grid point will depend on the sparsity of measurements that are used as input to the mapping algorithm for that position (Kettle et al., 1999). Uncertainty
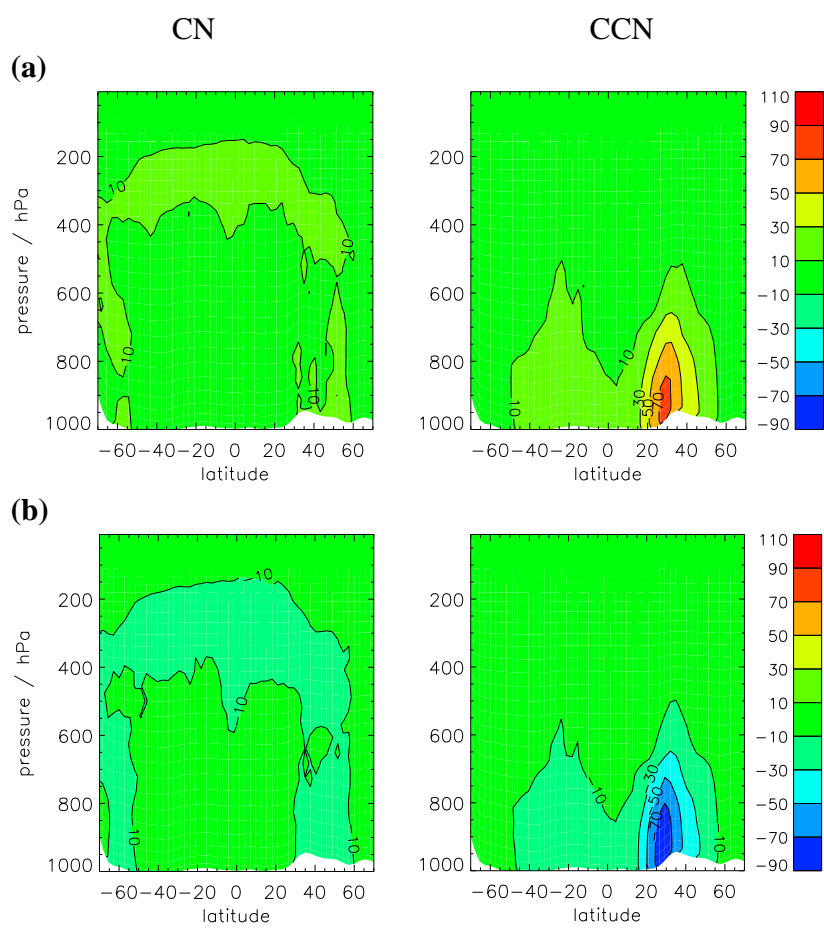

Fig. 14. Monthly mean change in zonal mean $\mathrm{CN}$ (\% change) and $\mathrm{CCN}$ (absolute change $\left(\mathrm{cm}^{-3}\right)$ at $0.2 \%$ supersaturation) concentrations for December 1995. (a) All sulfur emissions $125 \%$ of the baseline emissions; (b) all sulfur emissions $75 \%$ of the baseline emissions.

is generally largest at higher latitudes due to the sparsity of data points and the high spatial and temporal variability in DMS concentrations that occur there. Kettle and Andreae (2000) estimated that overall uncertainty in the sea-air gas flux of DMS is as large as 50\%.

To study the effect of these uncertainties in the model, the emission rates for all sulfur-bearing gases were varied by $25 \%$ from the baseline emissions. All anthropogenic sulfur was assumed to be gaseous $\mathrm{SO}_{2}$. This study neglects feedbacks between changes in $\mathrm{SO}_{2}$ concentrations and gas phase production of $\mathrm{H}_{2} \mathrm{O}_{2}$.

Figure 14 shows that $\mathrm{CN}$ concentrations in the tropical UT between about 200 and $400 \mathrm{hPa}$ and in the NH and SH midlatitudes are most sensitive to changes in emissions. $\mathrm{CCN}$ concentrations are most sensitive to changes in emissions between the surface and about $500 \mathrm{hPa}$. Changing the emission rate by $25 \%$ causes about a $10 \%$ change in global mean sulfate and sea salt $\mathrm{CN}$ and a $15 \%$ change in global mean MBL sulfate and sea salt $\mathrm{CCN}$ concentrations. This change in $\mathrm{CCN}$ is larger than the change caused by uncertainties in the nucleation rates (Sect. 5.1), although the changes in $\mathrm{CN}$ are less than those due to microphysical processes.

Figure 15 shows the percentage change in global mean $\mathrm{CN}$ and $\mathrm{CCN}$ concentrations for a $25 \%$ and $50 \%$ change in global emissions of sulfur gases. Changing the global emission 


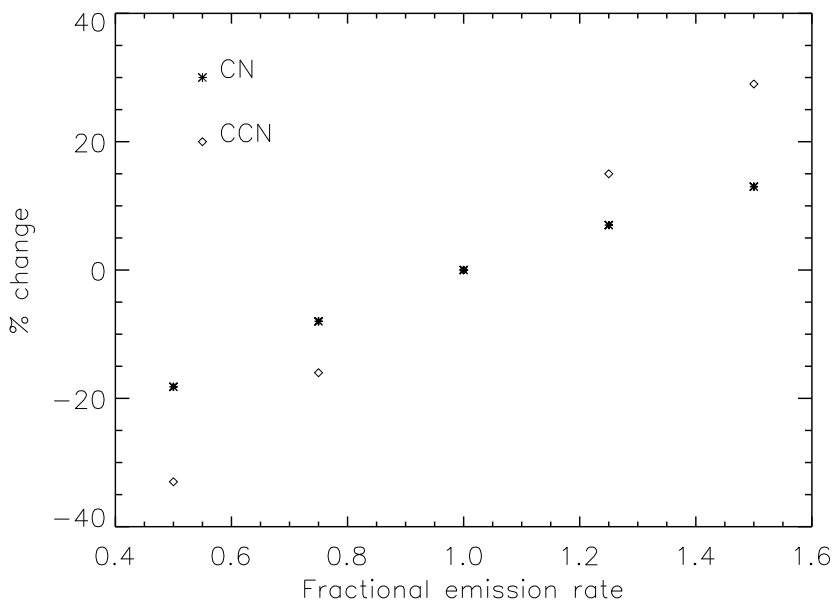

Fig. 15. Percentage change in globally averaged MBL monthly mean sea salt and sulfate $\mathrm{CN}$ and $\mathrm{CCN}$ ( $0.2 \%$ supersaturation) concentrations for December 1995 for sulfur emission rates of between $50 \%$ and $150 \%$ of baseline emissions.

rates has a greater impact on $\mathrm{CCN}$ concentrations than $\mathrm{CN}$ concentrations. Changing emission rates appears to have an almost linear effect on changes in $\mathrm{CCN}$ concentrations. A $50 \%$ change in emission rates changes global mean MBL $\mathrm{CN}$ concentrations by about $15-20 \%$ and global mean MBL CCN concentrations by about $30-35 \%$, while a $25 \%$ change in emission rates changes global mean MBL CN concentrations by about $10 \%$ and global mean MBL CCN concentrations by about $15 \%$.

Figure 16 shows number-size distributions and $\mathrm{CCN}$ spectra over polluted Northern Europe for different sulfur emission rates and percentage of anthropogenic sulfur emitted as primary particles. In the polluted BL including $1 \%$ of sulfur emissions as particulates has a much greater impact on the size distribution than changing emission rates by $25 \%$. When the sulfur flux is changed the general shape of the size distribution is maintained, but with the distribution shifted up or down in number space. Including a percentage of sulfur emissions as particulates changes both the shape of the distribution and the overall particle concentration below about $1 \mu \mathrm{m}$. Over Europe, the number mean diameter shifts from about 50 to $15 \mathrm{~nm}$ diameter.

Together, Figs. 13 and 14 help to explain why the size distribution in the polluted $\mathrm{BL}$ changes much more in response to primary particles than to greater overall $\mathrm{SO}_{2}$ emissions. Changing $\mathrm{SO}_{2}$ leads to small changes in aerosol mass and number right through the troposphere, with peak changes in the UT. In contrast, primary sulfate particles are created immediately in the BL at sizes for which the coagulational scavenging rate is low, so a large fraction of the emitted particles survive.

Over the US both GLOMAP and a limited area model used by von Salzen et al. (2000) show between 30 and $60 \%$ decrease in $\mathrm{CCN}$ concentrations (depending on the supersaturation) for a $50 \%$ decrease in $\mathrm{SO}_{2}$ emissions. (a)

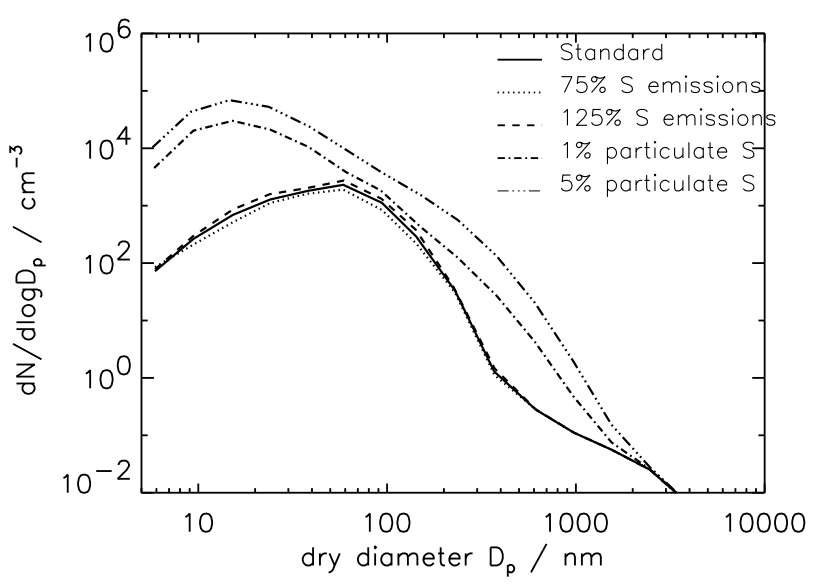

(b)

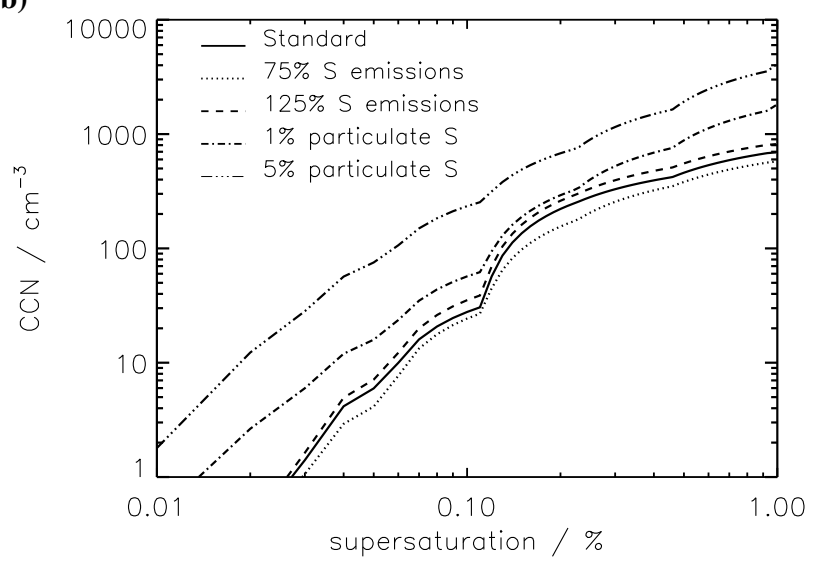

Fig. 16. Simulated monthly mean BL (bottom model level) sea salt and sulfate aerosol distributions over Northern Europe $\left(50-60^{\circ} \mathrm{N}\right.$, $\left.10-20^{\circ} \mathrm{E}\right)$ for December 1995 for different sulfur emission rates and percentages of particulate emissions. The baseline model run has $100 \%$ sulfur emissions and $0 \%$ of the sulfur emissions emitted as particulates. (a) Number-size distribution; (b) sea salt and sulfate $\mathrm{CCN}$ spectrum.

\subsection{Sensitivity to sea spray emission rate}

Sea spray particles range in size from 0.02 to $60 \mu \mathrm{m}$ diameter (Fitzgerald, 1991), but the climatic importance of sea spray through the aerosol indirect effect, depends largely on the number of particles with sizes of 100 to $200 \mathrm{~nm}$ diameter (O'Dowd et al., 1999). An accurate description of sea spray flux in this size range is essential to determine the influence of sea spray on the aerosol indirect effect. Under clean marine conditions sea spray particles may dominate the accumulation mode and contribute significantly to the $\mathrm{CCN}$ population (O'Dowd and Smith, 1993).

Estimates of the sea salt flux at any particle diameter vary by over an order of magnitude (Hoppel et al., 2002). GLOMAP uses the sea spray source function of Gong (2003), which produces realistic fluxes at particle sizes 


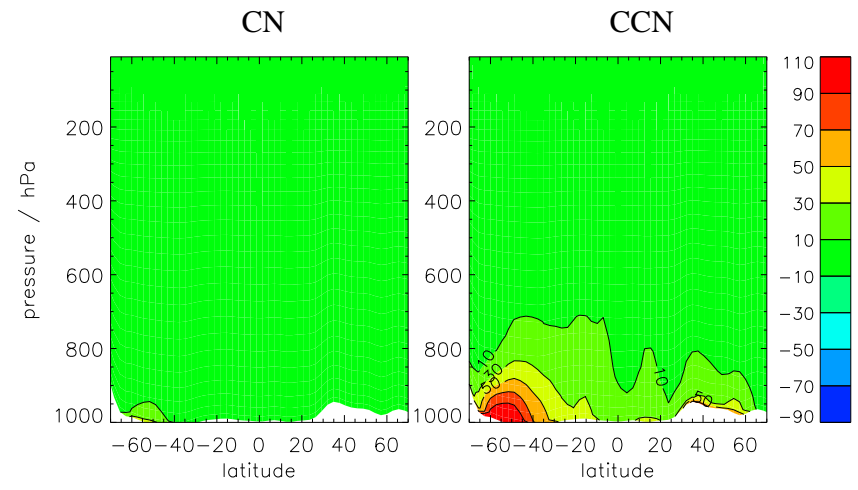

Fig. 17. Monthly mean change in zonal mean $\mathrm{CN}$ (\% change) and CCN (absolute change $\left(\mathrm{cm}^{-3}\right)$ at $0.2 \%$ supersaturation) concentrations for December 1995 for sea salt emissions an order of magnitude higher than in the baseline case.

between 0.07 and $20 \mu \mathrm{m}$ at $80 \%$ humidity (corresponding to approximately 0.035 and $10 \mu \mathrm{m}$ dry diameter). This parameterisation is an extension of the semi-empirical formulation of Monahan et al. (1986) to below $0.2 \mu \mathrm{m}$ diameter, where the original parametrisation was found to overestimate emissions of sub-micron sea spray particles. The non-dimensional adjustable parameter $(\Theta)$ that controls submicron emissions is set at 30 .

The effect of uncertainty in the sea spray emission flux is investigated by changing the source strength by an order of magnitude. Figure 17 shows that for an order of magnitude increase in sea spray flux, sulfate and sea salt $\mathrm{CCN}$ concentrations below about $700 \mathrm{hPa}$ increase by up to $100 \mathrm{~cm}^{-3}$. In remote marine areas this is a larger change in $\mathrm{CCN}$ than that caused by changing sulfur gas emission rates by $25 \%$. In the MBL, CN concentrations generally increase by less than $5 \%$ for an order of magnitude increase in sea spray emissions, although changes of up to $10 \%$ between 40 and $60^{\circ} \mathrm{S}$ are predicted. Changes in $\mathrm{CN}$ are negligible above the $\mathrm{BL}$.

Figure 18 compares the effect on North Atlantic and Southern Ocean MBL number-size distributions of changing sulfur and sea spray emissions. There is an obvious difference between the two oceans in the number of particles in the accumulation mode $(\sim 100-200 \mathrm{~nm})$. In the North Atlantic, the accumulation mode is dominated by sulfate aerosol, and even large increases in sea spray flux have little impact. In contrast, the Southern Ocean accumulation mode number increases from $\sim 10-50 \mathrm{~cm}^{-3}$ to $\sim 100-250 \mathrm{~cm}^{-3}$ for an order of magnitude increase in sea spray emissions. Accumulation mode number in the Southern Ocean is also sensitive to the value of $\Theta$ (non-dimensional) in the paramateristaion of Gong et al. (2003). Changing $\Theta$ from 40 to 15 causes an order of magnitude increase in sub-micron sea spray emissions and an increase in accumulation mode number to about 50$100 \mathrm{~cm}^{-3}$. In both oceans the increase in accumulation mode number is largely offset by decreases in Aitken number, and so total number remains relatively unchanged. Reductions (a)

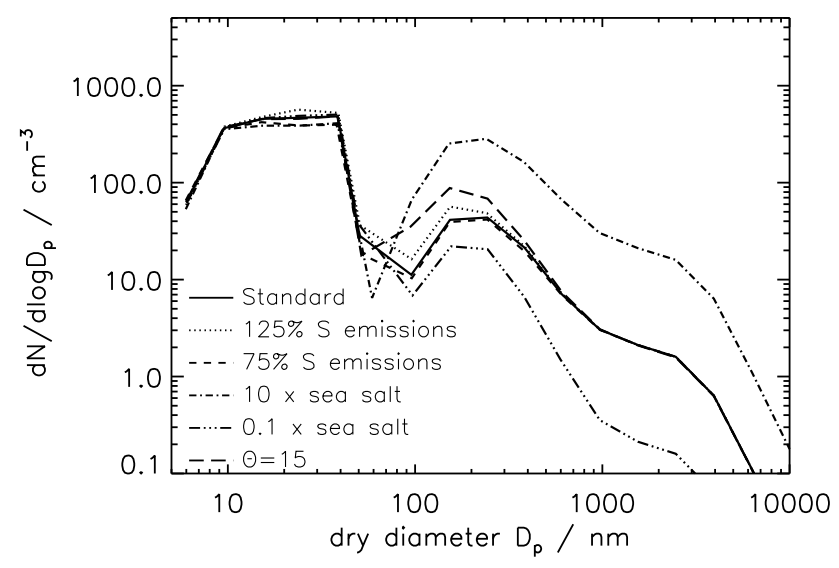

(b)

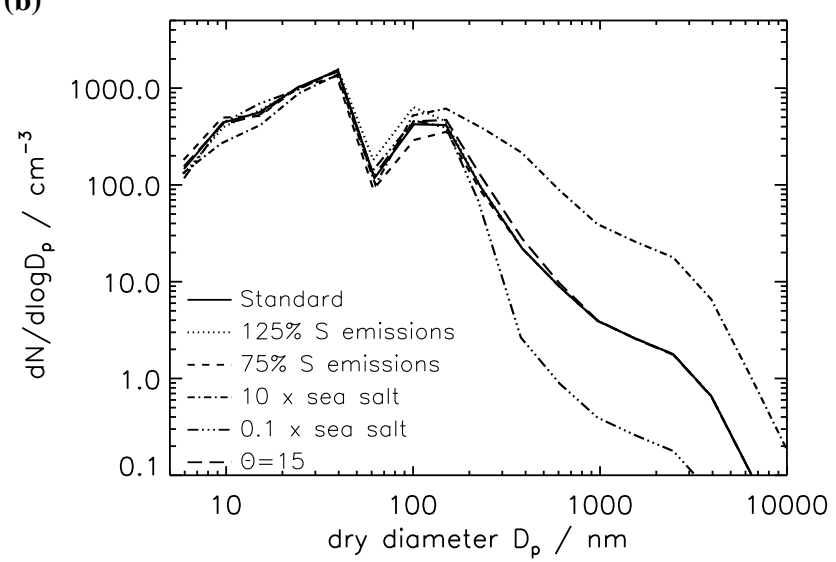

Fig. 18. Simulated monthly averaged MBL number-size distributions (bottom model level) for December 1995 over (a) Southern Ocean $\left(50-55^{\circ} \mathrm{S}, 150-155^{\circ} \mathrm{E}\right)$; (b) North Atlantic $\left(40-45^{\circ} \mathrm{N}, 30\right.$ $35^{\circ} \mathrm{W}$ ) for different sulfur and sea spray emission rates.

in Aitken mode particle concentrations are caused by the increase in the BL coagulation sink causing faster scavenging of smaller particles.

Our simulations show that switching off sea spray flux changes global mean $\mathrm{CN}$ number by less than 1\% (not shown). This result is different to that obtained by Gong and Barrie (2003), who saw BL number increase between 30 and $50 \%$ in the North Atlantic and Southern Oceans when no sea spray emissions were included. When the sea spray emission flux is turned off in GLOMAP there is still sufficient nss-sulfate aerosol in the $\mathrm{BL}$ to provide the necessary condensation sink to keep gas-phase $\mathrm{H}_{2} \mathrm{SO}_{4}$ concentrations below the binary $\mathrm{H}_{2} \mathrm{SO}_{4}-\mathrm{H}_{2} \mathrm{O}$ nucleation threshold. Aerosol nucleation occurs predominantly in the cold FT and UT in GLOMAP, but the short lifetime of sea spray is such that only a very small fraction is transported into these cold regions. $\mathrm{CN}$ concentrations in the UT, and hence the rate of entrainment of aerosol from the FT to the BL, is therefore not changed when the sea spray emission flux is reduced. 


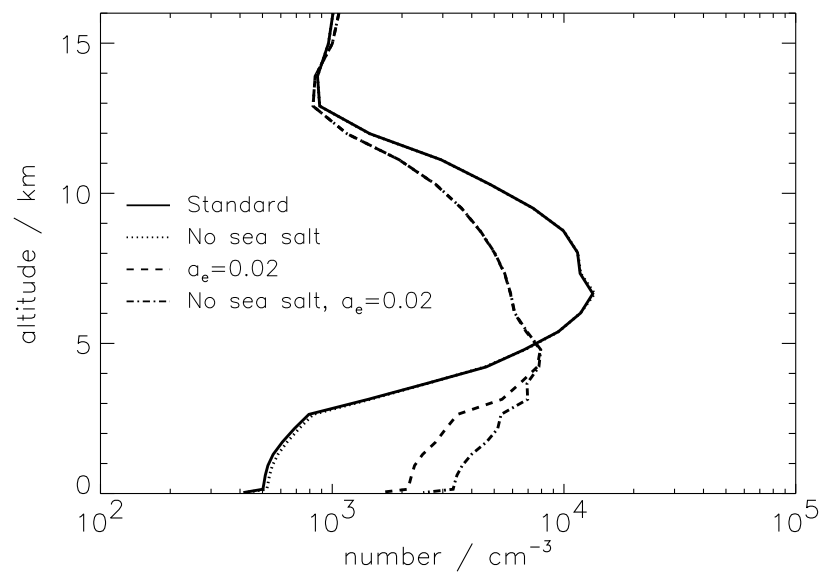

Fig. 19. Simulated monthly mean vertical profile of $\mathrm{CN}$ concentrations at STP in the Southern Ocean $\left(50-55^{\circ} \mathrm{S}, 150-155^{\circ} \mathrm{E}\right)$ during December 1995 for different accommodation coefficients and sea spray emissions.

The different response of $\mathrm{CN}$ to changes in sea spray in our simulations and those of Gong and Barrie (2003) is due to the different $\mathrm{H}_{2} \mathrm{SO}_{4}$ accommodation coefficients used. Figure 19 shows the effect of changes in sea spray emissions on vertical profiles of CN number over the Southern Ocean for different accommodation coefficients. When $a_{e}$ is reduced to 0.02 (as used by Gong and Barrie (2003)), removing sea spray emissions causes an increase in BL CN number of about $50 \%$. Such a low value of $a_{e}$ in GLOMAP allows nucleation to occur much closer to the surface (see Sect. 5.1.1) so when sea salt emissions are reduced the reduction in the coagulation sink allows more of these particles to survive to $\mathrm{CN}$ sizes.

\section{Summary}

The sensitivity of the sulfate and sea salt aerosol size distribution and the spatial distributions of $\mathrm{CN}$ and $\mathrm{CCN}$ abundances to changes in the rates of microphysical processes and emission strengths has been investigated using a global model with a sectional aerosol scheme.

The sensitivity of sulfate and sea salt $\mathrm{CN}$ and $\mathrm{CCN}$ concentrations is summarised in Fig. 20. In general, model predictions of sulfate and sea salt $\mathrm{CN}$ and $\mathrm{CCN}$ concentrations are sensitive to realistic uncertainties in both emissions and microphysical processes. Global mean sulfate and sea salt $\mathrm{CN}$ concentrations are dominated in these simulations by the very high concentrations of sulfuric acid aerosol in the free and upper troposphere where nucleation rates are highest. Global mean $\mathrm{CN}$ is therefore sensitive to the rate of nucleation, the critical cluster size and the accommodation coefficient of sulfuric acid but relatively insensitive to the activation process in clouds or the emission of primary sulfate particle from surface sources. Global $\mathrm{CN}$ is also sensitive to the process of wet scavenging of aerosol, which controls the particle surface area in the FT and UT, and hence the (a) Global mean $\mathrm{CN}$

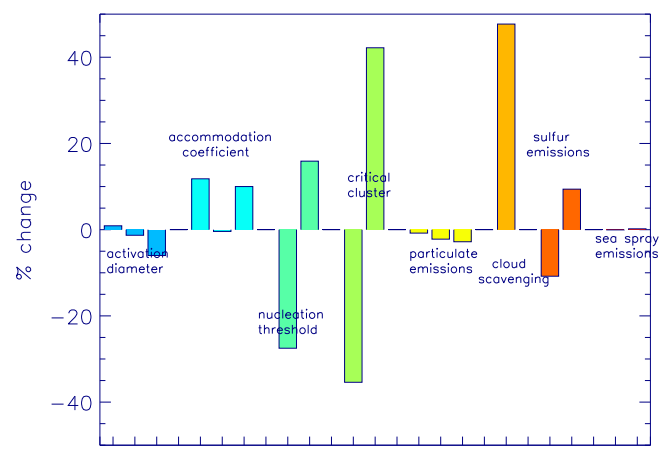

(b) Surface mean $\mathrm{CN}$

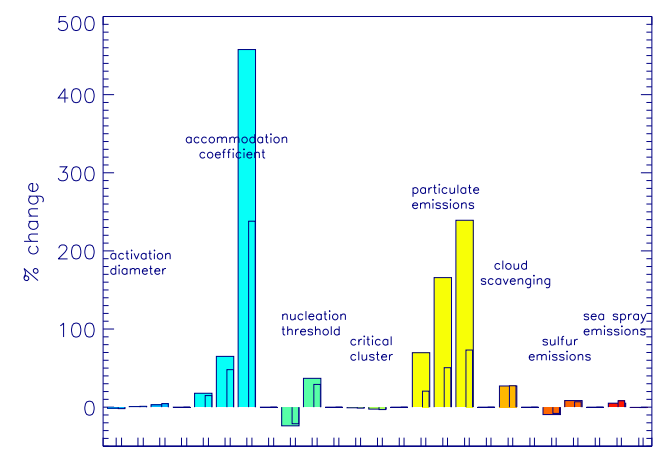

(c) Surface mean $\mathrm{CCN}(0.2 \%$ supersaturation)

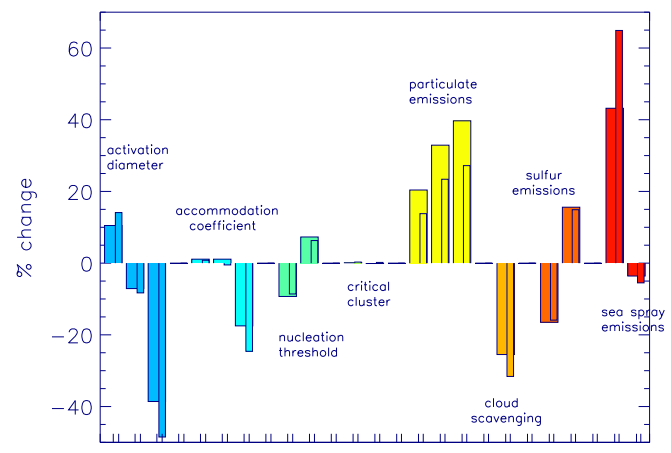

Fig. 20. Percentage change in air-mass weighted monthly mean $\mathrm{CN}$ and $\mathrm{CCN}$ (at $0.2 \%$ supersaturation) concentrations during December 1995 for changes in model parameters. Thick bars show global means and thin bars (b and $\mathbf{c}$ ) show means over the oceans only. The model parameters were varied (left to right in the above panels) as follows: activation diameter for in-cloud oxidation - 0.04, 0.06, $0.08 \mu \mathrm{m}$ (baseline model run $0.05 \mu \mathrm{m}$ ); accommodation coefficient $-0.65,0.3,0.02$ (baseline 1.0); $\mathrm{H}_{2} \mathrm{SO}_{4}$ nucleation threshold 2 and 0.5 times the baseline; nucleation critical cluster size -50 and 10 molecules (baseline 100 molecules $\mathrm{H}_{2} \mathrm{SO}_{4}$ ); particulate emissions 1,3 and $5 \%$ of anthropogenic $\mathrm{SO}_{2}$ (baseline $0 \%$ ); cloud scavenging activation diameter $-0.1 \mu \mathrm{m}$ (baseline $0.206 \mu \mathrm{m}$ ); sulfur emissions $-75 \%$ and $125 \%$ of the baseline; sea spray emissions -10 and 0.1 times the baseline flux. 
competition for available sulfuric acid vapour between particle formation and condensation to existing particles.

Global mean surface sulfate and sea salt $\mathrm{CN}$ concentrations in these simulations are dominated by sulfuric acid aerosol and are most sensitive to uncertainties in primary sulfate emissions and the accommodation coefficient. The lowest value of the sulfuric acid accommodation coefficient used here $\left(a_{e}=0.02\right)$ is probably an extreme choice, although even a modest value of 0.3 (decreased from 1.0) increases mean MBL CN concentrations by $48 \%$. Primary sulfate emissions have the potential to change the global mean surface sulfate $\mathrm{CN}$ concentration by a factor 2 or more (mean MBL CN changes by up to $75 \%$ ), and changes of up to a factor 20 can occur in polluted regions. $\mathrm{CN}$ are also produced from nonsulfate sources. Further studies involving more aerosol types and sources are needed to put these sensitivities in context.

Changing microphysical processes within reasonable uncertainty ranges, changes predicted mean MBL sea salt and sulfate CCN concentrations by 10 to $60 \%$ and has a similar effect as uncertainties in emissions of sulfur species. Cloud processes are very important in controlling CCN concentrations. In-cloud oxidation (causing mass addition to aerosols by $\mathrm{SO}_{2}$ oxidation in droplets) moves aerosols from Aitken mode sizes to the accumulation mode more rapidly than is achieved through condensation of sulfuric acid and coagulation. We have investigated how uncertainties in the activation diameter of aerosols in clouds affects $\mathrm{CCN}$ at a particular supersaturation. The activation diameter is in reality controlled by cloud-scale updraught velocities, which are difficult to predict in global models. Reasonable uncertainties in the activation diameter in our model lead to changes in global MBL sulfate and sea salt CCN concentrations of as much as $50 \%$ at a given supersaturation. Scavenging of aerosol by precipitating clouds also exerts a strong control on $\mathrm{CCN}$ abundances.

Sulfate-derived CCN concentrations are particularly sensitive to assumptions made about the production of primary sulfate particles in pollution plumes below the scale of the model grid. Reasonable assumptions about the gridmean concentration of such particles leads to uncertainties in global mean sulfate-derived CCN of as much as $40 \%$ (up to a $27 \%$ change in mean MBL sulfate and sea salt $\mathrm{CCN}$ ), with local changes of more than $100 \%$ in polluted regions. This uncertainty is larger than the change in sulfate-derived CCN (about $\pm 15 \%$ global surface mean) caused by a $\pm 25 \%$ change in total sulfur emissions. Our model therefore suggests that the mode of sulfate emission is as important for $\mathrm{CCN}$ abundance as the magnitude. A large fraction of $\mathrm{CCN}$ sized particles are likely to be composed of material other than sulfate and sea salt over continental regions. Here we assume that a $1-5 \%$ emission of $\mathrm{SO}_{2}$ as particulates is used as an estimate solely for sub-grid nucleation of sulfate in power plant plumes.

We have also shown that the altitude of the upper tropospheric $\mathrm{CN}$ layer is sensitive to a number of microphysical processes. Changes in the nucleation rate, the condensation rate and the size of freshly nucleated clusters within realistic ranges leads to changes in the altitude of peak $\mathrm{CN}$ concentrations by up to $3 \mathrm{~km}$.

\section{Implications and outlook}

This study has focussed on the uncertainty in $\mathrm{CN}$ and CCN concentrations due to realistic uncertainties in the microphysical processes that control the size distribution of sulfate and sea salt aerosol. One might argue that the use of a global aerosol microphysics model (as opposed to a simpler aerosol parameterisation in a climate model) has simply extended the list of uncertain parameters without actually reducing the overall uncertainty. At this stage in the development and evaluation of aerosol microphysics models, this is true. However, it needs to be remembered that, ultimately, it is changes in the particle size distribution that determine the magnitude of the direct and indirect aerosol forcing. Our understanding of what controls changes in the aerosol size distribution is far from complete. Without such understanding we are not in a position to say that changes in forcing in the industrial period can be accurately predicted using models that simulate only aerosol mass, which has been assumed in climate change attribution studies to date (Houghton et al., 2001). The temporal pattern of radiative forcing over the last 100 years is critical for the attribution of climate change. Further development of such microphysical models, the addition of more aerosol components, and the improvement of schemes to treat the most uncertain processes is therefore essential.

The uncertainties in predicted sulfate and sea salt CCN are large compared with changes that are likely to be important for the aerosol direct and indirect radiative forcing (Pan et al., 1997, 1998). For example, changes in lower atmospheric global mean cloud drop number in response to changing aerosol emissions since 1860 are predicted by general circulation models to be of the order $70 \%$ (A. Jones, personal communication). We estimate the uncertainty in global MBL mean sulfate and sea salt CCN concentrations to be as much as $60 \%$, although the uncertainty in total $\mathrm{CCN}$ may be lower in a model that considers the complete range of primary aerosol emissions.

A useful extension to this work in the context of climate change would be to quantify the extent to which these uncertainties restrict our ability to quantify changes in radiative forcing and cloud properties in response to changes in emissions. For example, whether the response of CCN to changes in sulfur emissions is different when high or low nucleation rates are used or if high or low primary sulfate emissions are assumed. We also need to determine whether any of these microphysical processes or the nature of emissions has changed over the last 100 years. For example, the contribution of primary sulfate aerosol to boundary layer CCN 
is likely to have changed as emissions have shifted from domestic sources to power plants. Such changes may have as important an effect on radiative forcing as gross changes in emissions themselves. Neither of these processes affecting particle number can be studied with a mass-only aerosol scheme.

Our work points towards a number of processes that require better representation in a global model. The bulk of the uncertainty in predicted sulfate and sea salt $\mathrm{CCN}$ concentrations arises from the contribution of primary sulfate particles to the grid mean in the model and from the uncertainty in the effect of clouds on the aerosol size distribution. Both of these processes present a particularly challenging problem for global models. Accurate descriptions of cloud processes will be essential for quantitative estimates of global $\mathrm{CCN}$ number. In addition, estimation of total $\mathrm{CCN}$ number will require a model which contains the full range of aerosol constituents. Over polluted continental regions, carbonaceous aerosol may be the dominant contributor to total $\mathrm{CCN}$.

Conclusions regarding the most important uncertainties are valid only in so far as the mechanisms used in the model are realistic. In particular, our model assumes that binary homogeneous nucleation of sulfuric acid-water aerosol is the only particle formation mechanism. Because the nucleation rate according to this mechanism peaks at the low temperatures in the upper troposphere, our simulations suggest that boundary layer aerosol is relatively insensitive to the nucleation rates. However, observations and model studies suggest that particle formation can occur in the continental boundary layer, perhaps accelerated by the presence of gaseous organic compounds (Antilla et al., 2004). In Sect. 5.4 we stated that our model tends to under-predict continental boundary layer $\mathrm{CN}$ concentrations and that this discrepancy may be accounted for by primary sulfate particles. However, alternative aerosol nucleation mechanisms and carbonaceous aerosol emissions may also help to explain such discrepancies. Much work is needed to identify the mechanism of particle formation throughout the atmosphere so that we can understand observed aerosol abundances and predict changes.

Edited by: A. Nenes

\section{References}

Adams, P. and Seinfeld, J.: Predicting global aerosol size distributions in general circulation models, J. Geophys. Res.-Atmos., 107, 4370, doi:10.1029/2001JD001010, 2002.

Adams, P. and Seinfeld, J.: Disproportionate impact of particulate emissions on global cloud condensation nuclei concentrations, Geophys. Res. Lett., 30, 43-46, 2003.

Antilla, T., Kerminen, V.-M., Kulmala, M., Laaksonen, A., and O'Dowd, C.: Modelling the formation of organic particles in the atmosphere, Atmos. Chem. Phys., 4, 1071-1083, 2004,

SRef-ID: 1680-7324/acp/2004-4-1071.
Ayers, G. and Gillett, R.: DMS and its oxidation products in the remote marine atmosphere: implications for climate and atmospheric chemistry, J. Sea Res., 43, 275-286, 2000.

Benkovitz, C., Scholtz, M., Pacyna, J., Tarrasón, L., Dignon, J., Voldner, E., Spiro, P., Logan, J., and Graedel, T.: Global gridded inventories of anthropogenic emissions of sulfur and nitrogen, J. Geophys. Res.-Atmos., 101, 29 239-29 253, 1996.

Binkowski, F. and Shankar, U.: The regional particulate matter model, 1, Model description and preliminary results, J. Geophys. Res.-Atmos., 100, 26 191-26 209, 1995.

Boucher, O. and Anderson, T.: General circulation model assessment to the sensitivity of direct climate forcing by anthropogenic sulfate aerosols to aerosol size and chemistry, J. Geophys. Res.Atmos., 100, 26 117-26 134, 1995.

Brock, C., Washenfelder, R., Trainer, M., Ryerson, T., Wilson, J., Reeves, J., Huey, L., Holloway, J., Parrish, D., Hübler, G., and Fehsenfeld, F.: Particle growth in the plumes of coal-fired power plants, J. Geophys. Res.-Atmos., 107, 4155-4169, 2002.

Capaldo, K., Kasibhatla, P., and Pandis, S.: Is aerosol production within the marine boundary layer sufficient to maintain observed concentrations?, J. Geophys. Res.-Atmos., 104, 34833500, 1999.

Clarke, A., Varner, J., Eisele, F., Mauldin, R., Tanner, D., and Litchy, M.: Particle production in the remote marine atmosphere: Cloud outflow and subsidence during ACE 1, J. Geophys. Res.Atmos., 103, 16 397-16409, 1998.

Clement, C., Kulmala, M., and Vesala, T.: Theoretical considerations on sticking probabilities, J. Aerosol Sci., 27, 869-882, 1996.

Coffman, D. and Hegg, D.: A preliminary study of the effect of ammonia on particle nucleation in the marine boundary layer, J. Geophys. Res.-Atmos., 100, 7147-7160, 1995.

Däumer, B., Niessner, R., and Klockow, C.: Laboratory studies of the influence of thin organic films on the neutralization reaction of $\mathrm{H}_{2} \mathrm{SO}_{4}$ aerosol with ammonia, J. Aerosol Sci., 23, 315-325, 1992.

Dietz, R. and Wieser, R.: Sulfate formation in oil fired power plant plumes. Volume 1: Parameters affecting primary sulfate emissions and a model for predicting emissions and plume opacity, Tech. rep., Electric Power Research Institute, 1983.

Easter, R. and Peters, L.: Binary homogeneous nucleation: Temperature and relative humidity fluctuations, non-linearity and aspects of new particle production in the atmosphere, J. Appl. Meteorol., 33, 775-784, 1994.

Easter, R., Ghan, S., Zhang, Y., Saylor, R., Chapman, E., Laulainen, N., Abdul-Razzak, H., Leung, L., Bian, X., and Zaveri, R.: MIRAGE: Model description and evaluation of aerosols and trace gases, J. Geophys. Res.-Atmos., 109, D20210, doi:10.1029/2004JD004571, 2004.

Eliassen, A. and Saltbones, J.: Modelling of long range transport of sulfur over Europe: A two year model run and some model experiments, Atmos. Environ., 17, 1457-1473, 1983.

EMEP: Airborne transboundary transport of sulfur and nitrogen species over Europe - model descriptions and calculations, Tech. Rep. 80, EMEP, 1989.

EPA: National air quality and emissions trends report, Tech. Rep. Rep. EPA 454/R-00-0003, Environmental Protection Agency, 2000.

Fitzgerald, J.: Marine aerosols: A review, Atmos. Environ., 25, 
533-545, 1991.

Flossmann, A.: The scavenging of 2 different types of marine aerosol-particles calculated using a 2-dimensional detailed cloud model, Tellus, Ser. B, 43, 301-321, 1991.

Gong, S.: A parameterization of sea-salt aerosol source function for sub- and super-micron particles, Global Biogeochem. Cycles, 17, 1097-1103, 2003.

Gong, S. and Barrie, L.: Simulating the impact of sea salt on global nss sulphate aerosols, J. Geophys. Res.-Atmos., 108, 4516-4533, 2003.

Gong, S., Barrie, L., and Blanchet, J.-P.: Modeling sea-salt aerosols in the atmosphere 1. Model Development, J. Geophys. Res.Atmos., 102, 3805-3818, 1997.

Gong, S., Barrie, L., Blanchet, J.-P., von Salzen, K., Lohmann, U., Lesins, G., Spacek, L., Zhang, L., Girard, E., Lin, H., Leaitch, R., Leighton, H., Chylek, P., and Huang, P.: Canadian Aerosol Module: A size-segregated simulation of atmospheric aerosol processes for climate and air quality models 1. Module development, J. Geophys. Res.-Atmos., 108, 4007, doi:10.1029/2001JD002002, 2003.

Gras, J.: CN, CCN and particle size in Southern Ocean air at Cape Grim, Atmos. Res., 35, 233-251, 1995.

Hoppel, W., Frick, G., and Larson, R.: Effect of non-precipitating clouds on the aerosol size distribution, Geophys. Res. Lett., 13, 125-128, 1986

Hoppel, W., Frick, G., and Fitzgerald, J.: Surface source function for sea-salt aerosol and aerosol dry deposition to the ocean surface, J. Geophys. Res.-Atmos., 107, 4382-4398, 2002.

Houghton, J. T., Ding, Y., Griggs, D. J., Noguer, M., van der Linden, P. J., Xiaosu, D., Maskell, K., and Johnson, C. A. (Eds.): Intergovernmental Panel on Climate Change, Climate Change 2001: The Scientific Basis, Cambridge University Press, New York, 2001.

Jacobson, M.: GATOR-GCMM: A global - through urban - scale air pollution and weather forecast model 1. Model design and treatment of subgrid soil, vegetation, roads, rooftops, water, sea ice, and snow, J. Geophys. Res.-Atmos., 106, 5385-5401, 2001.

Jefferson, A., Eisele, F., Ziemann, P., Weber, R., Marti, J., and McMurry, P.: Measurements of the $\mathrm{H}_{2} \mathrm{SO}_{4}$ mass accommodation coefficient onto polydisperse aerosol, J. Geophys. Res.-Atmos., 102, 19021-19028, 1997.

Katoshevski, D., Nenes, A., and Seinfeld, J.: A study of processes that govern the maintenance of aerosols in the marine boundary layer, J. Aerosol Sci., 30, 503-532, 1999.

Kerminen, V.-M. and Wexler, A.: Growth behavior of the marine submicron boundary layer aerosol, J. Geophys. Res.-Atmos., 102, 18 813-18 825, 1997.

Kettle, A. and Andreae, M.: Flux of dimethylsulfide from the oceans: A comparison of updated data sets and flux models, J. Geophys. Res.-Atmos., 105, 26 793-26 808, 2000.

Kettle, A., Andreae, M., Amouroux, D., Andreae, T., Bates, T., Berresheim, H., Bingemer, H., Boniforti, R., Curran, M., DiTullio, G., Helas, G., Jones, G., Keller, M., Kiene, R., Leck, C., Levasseur, M., Malin, G., Maspero, M., Matrai, P., McTaggart, A., Mihalopoulos, N., Nguyen, B., Novo, A., Putaud, J., Rapsomanikis, S., Roberts, G., Schebeske, G., Sharma, S., Simö, R., Staubes, R., Turner, S., and Uher, G.: A global database of sea surface dimethylsulfide (DMS) measurements and a procedure to predict sea surface DMS as a function of latitude, longitude and month, Global Biogeochem. Cycles, 13, 399-444, 1999.

Kiehl, J. and Briegleb, B.: The relative roles of sulfate aerosols and greenhouse gases in climate forcing, Science, 260, 311-314, 1993.

Kulmala, M., Laaksonen, A., and Pirjola, L.: Parameterizations for sulfuric acid/water nucleation rates, J. Geophys. Res.-Atmos., 103, 8301-8307, 1998.

Kulmala, M., Vehkamäki, H., Petajda, T., Dal Maso, M., Lauri, A., Kerminen, V., Birmili, W., and McMurry, P.: Formation and growth rates of ultrafine atmospheric particles: a review of observations, J. Aerosol Sci., 35, 143-176, 2004.

Liss, P. and Merlivat, L.: The Role of Air-Sea Exchange in Geochemical Cycling, chap. Air-sea gas exchange rates: Introduction and synthesis, pp. 113-127, D. Reidel, Norwell, Mass., 1986.

Marti, J., Jefferson, A., Cai, X., Richert, C., McMurry, P., and Eisele, F.: $\mathrm{H}_{2} \mathrm{SO}_{4}$ vapour pressure of sulfuric acid and ammonium sulfate solutions, J. Geophys. Res.-Atmos., 102, 37253735, 1997.

McMurry, P.: A review of atmospheric aerosol measurements, Atmos. Environ., 34, 1959-1999, 2000.

Monahan, E., Spiel, D., and Davidson, K.: Oceanic Whitecaps, chap. A model of marine aerosol generation via whitecaps and wave disruption, pp. 167-174, D. Reidel, Norwell, Mass., 1986.

Myhre, G., Stordal, F., Berglen, T., Sundet, J., and Isaksen, I.: Uncertainties in the Radiative Forcing Due to Sulfate Aerosols, J. Atmos. Sci., 61, 485-498, 2004.

Napari, I., Noppel, M., Vehkamäki, H., and Kulmala, M.: An improved model for ternary nucleation of sulfuric acid-ammoniawater, J. Chem. Phys., 116, 4221-4227, 2002.

Nemesure, S., Wagener, R., and Schwartz, S.: Direct radiative forcing of climate by the anthropogenic sulfate aerosol: Sensitivity to particle size, composition and relative humidity, J. Geophys Res.-Atmos., 100, 26 105-26 116, 1995.

Nilsson, E., Pirjola, L., and Kulmala, M.: The effect of atmospheric waves on aerosol nucleation and size distribution, J. Geophys. Res.-Atmos., 105, 19917-19926, 2000.

O'Dowd, C. and Smith, M.: Pysio-chemical properties of aerosols over the North Atlantic: Evidence for wind-speed related submicron sea-salt aerosol production, J. Geophys. Res.-Atmos., 98, 1137-1149, 1993.

O'Dowd, C., Lowe, J., Smith, M., and Kaye, A.: The relative importance of non-sea-salt sulphate and sea-salt aerosol to the marine cloud condensation nuclei population: An improved multicomponent aerosol-cloud droplet parametrization, Q. J. R. Meteorol. Soc., 125, 1295-1313, 1999.

Pan, W., Tatang, M., McRae, G., and Prinn, R.: Uncertainty analysis of direct radiative forcing by anthropogenic sulfate aerosols, $\mathrm{J}$. Geophys. Res.-Atmos., 102, 21 915-21 924, 1997.

Pan, W., Tatang, M., McRae, G., and Prinn, R.: Uncertainty analysis of indirect radiative forcing by anthropogenic sulfate aerosols, J. Geophys. Res.-Atmos., 103, 3815-3823, 1998.

Pandis, S., Russell, L., and Seinfeld, J.: The relationship between DMS flux and CCN concentration in remote marine regions, J. Geophys. Res.-Atmos., 99, 16 945-19957, 1994.

Pilinis, C., Pandis, S., and Seinfeld, J.: Sensitivity of direct climate forcing by atmospheric aerosols to aerosol size and composition, J. Geophys. Res.-Atmos., 100, 18 739-18 754, 1995.

Pöschl, U., Canagaratna, M., Jayne, J., Molina, L., Worsnop, D., Kolb, C., and Molina, M.: Mass accommodation coefficient of 
$\mathrm{H}_{2} \mathrm{SO}_{4}$ vapour on aqueous sulfuric acid surfaces and gaseous difussion coefficient of $\mathrm{H}_{2} \mathrm{SO}_{4}$ in $\mathrm{N}_{2} / \mathrm{H}_{2} \mathrm{O}$, J. Phys. Chem. A, 102, 10 082-10 089, 1998.

Raes, F.: Entrainment of free tropsospheric aerosols as a regulating mechanism for cloud condensation nuclei in the remote marine boundary layer, J. Geophys. Res.-Atmos., 100, 2893-2903, 1995.

Raes, F., Van Dingenen, R., Vignati, E., Wilson, J., Putaud, J.-P., Seinfeld, J., and Adams, P.: Formation and cycling of aerosols in the global troposphere, Atmos. Environ., 34, 4215-4240, 2000.

Rogers, R. and Yau, M.: Short course in cloud physics, chap. Formation of cloud drops, Elsevier Science Ltd, 1989.

Russell, L., Pandis, S., and Seinfeld, J.: Aerosol production and growth in the marine boundary layer, J. Geophys. Res.-Atmos., 99, 20 989-21 003, 1994.

Saeger, M., Langstaff, J., Walters, R., Modica, L., Zimmerman, D., Fratt, D., Dulleba, D., Ryan, R., Demmy, J., Tax, W., Sprague, D., Mudgett, D., and Werner, A.: Development of the annual data and modelers' tape, Tech. rep., US Environmental Protection Agency, 1989.

Spracklen, D., Pringle, K., Carslaw, K., Chipperfield, M., and Mann, G.: A global off-line model of size resolved aerosol processes; I. Model development and prediction of aerosol properties, Atmos. Chem. Phys., 5, 2227-2252, 2005 ,

SRef-ID: 1680-7324/acp/2005-5-2227.

Stier, P., Feichter, J., Kinne, S., Kloster, S., Vignati, E., Wilson, J., Ganzeveld, L., Tegen, I., Werner, M., Balkanski, Y., Schulz, M., Boucher, O., Minikin, A., and Petzold, A.: The aerosol-climate ECHAM5-HAM, Atmos. Chem. Phys., 5, 1125-1156, 2005,

SRef-ID: 1680-7324/acp/2005-5-1125

Stockwell, D. and Chipperfield, M.: A tropospheric chemicaltransport model: Development and validation of the model transport schemes, Q. J. R. Meteorol. Soc., 125, 1747-1783, 1999.
Stolzenburg, M. and McMurry, P.: An ultrafine aerosol condensation nucleus counter, Aerosol Sci. Tech., 14, 48-65, 1991.

Tuovinen, J.-P., Banett, K., and Styve, H.: Transboundary Acidifying Pollution in Europe: Calculated Fields and Budgets 1985-93, Tech. rep., The UN Economic Commission for Europe (ECE) Cooperative Programme for Monitoring and Evaluation of the Long Range Transmission of Air Pollutants in Europe, Oslo, 1994.

Van Dingenen, R. and Raes, F.: Determination of the condensation accommodation coefficient of sulfuric acid on water-sulfuric acid aerosol, Aerosol Sci. Technol., 15, 93-106, 1991.

Vehkamäki, H., Kulmala, M., Napari, I., Lehtinen, K., Timmreck, C., Noppel, M., and Laaksonen, A.: An improved parametrization for sulfuric acid-water nucleation rates for tropospheric and stratospheric conditions, J. Geophys. Res.-Atmos., 107, 46224631, 2002.

von Salzen, K., Leighton, H., Ariya, P., Barrie, L., Gong, S., Blanchet, J.-P., Spacek, L., Lohmann, U., and Kleinman, L.: Sensitivity of sulphate aerosol size distributions and $\mathrm{CCN}$ concentrations over North America to $\mathrm{SO}_{\mathrm{x}}$ emissions and $\mathrm{H}_{2} \mathrm{O}_{2}$ concentrations, J. Geophys. Res.-Atmos., 105, 9741-9765, 2000.

Weber, R., McMurry, P., Eisele, F., and Tanner, D.: Measurement of expected nucleation precursor species and 3-500 $\mathrm{nm}$ diameter particles at Mauna Loa Observatory, Hawaii, J. Atmos. Sci., 52, 2242-2256, 1995.

Whitby, K.: The physical characteristics of sulfur aerosols, Atmos. Environ., 12, 135-159, 1978.

Yoon, Y. and Brimblecombe, P.: Modelling the contribution of sea salt and dimethyl sulfide derived aerosol to marine CCN, Atmos. Chem. Phys., 2, 17-30, 2002,

SRef-ID: 1680-7324/acp/2002-2-17. 